\title{
Upscaling instantaneous to daily evapotranspiration using modelled daily shortwave radiation for remote sensing applications: an artificial neural network approach
}

\author{
Loise Wandera $^{1,2}$, Kaniska Mallick ${ }^{1}$, Gerard Kiely ${ }^{3}$, Olivier Roupsard ${ }^{4,5}$, Matthias Peichl ${ }^{6}$, and Vincenzo Magliulo ${ }^{7}$ \\ ${ }^{1}$ Remote Sensing and Ecohydrological Modeling, Dept. ERIN, Luxembourg Institute of Science and \\ Technology, Belvaux, Luxembourg \\ ${ }^{2}$ Water Resources, Dept. ITC, University of Twente, Enschede, the Netherlands \\ ${ }^{3}$ Civil and Environmental Engineering Dept., and Environmental Research Institute, University College Cork, Cork, Ireland \\ ${ }^{4}$ CIRAD, UMR Eco\&Sols, 2 Place Viala, Montpellier, France \\ ${ }^{5}$ CATIE, Centro Agronómico Tropical de Investigación y Enseñanza, Turrialba, Cartago, Costa Rica \\ ${ }^{6}$ Department of Forest Ecology and Management, Swedish University of Agricultural Sciences, Umeå, Sweden \\ ${ }^{7}$ Consiglio Nazionale delle Ricerche, ISAFOM, Ercolano, Naples, Italy
}

Correspondence to: Kaniska Mallick (kaniska.mallick@gmail.com) and Loise Wandera (loise.wandera@list.lu)

Received: 11 July 2016 - Published in Hydrol. Earth Syst. Sci. Discuss.: 15 July 2016

Revised: 30 November 2016 - Accepted: 1 December 2016 - Published: 11 January 2017

\begin{abstract}
Upscaling instantaneous evapotranspiration retrieved at any specific time-of-day $\left(\mathrm{ET}_{i}\right)$ to daily evapotranspiration $\left(\mathrm{ET}_{\mathrm{d}}\right)$ is a key challenge in mapping regional ET using polar orbiting sensors. Various studies have unanimously cited the shortwave incoming radiation $\left(R_{\mathrm{S}}\right)$ to be the most robust reference variable explaining the ratio between $\mathrm{ET}_{\mathrm{d}}$ and $\mathrm{ET}_{i}$. This study aims to contribute in $\mathrm{ET}_{i}$ upscaling for global studies using the ratio between daily and instantaneous incoming shortwave radiation $\left(R_{\mathrm{Sd}} / R_{\mathrm{Si}}\right)$ as a factor for converting $\mathrm{ET}_{i}$ to $\mathrm{ET}_{\mathrm{d}}$.

This paper proposes an artificial neural network (ANN) machine-learning algorithm first to predict $R_{\mathrm{Sd}}$ from $R_{\mathrm{Si}}$ followed by using the $R_{\mathrm{Sd}} / R_{\mathrm{Si}}$ ratio to convert $\mathrm{ET}_{i}$ to $\mathrm{ET}_{\mathrm{d}}$ across different terrestrial ecosystems. Using $R_{\mathrm{Si}}$ and $R_{\mathrm{Sd}}$ observations from multiple sub-networks of the FLUXNET database spread across different climates and biomes (to represent inputs that would typically be obtainable from remote sensors during the overpass time) in conjunction with some astronomical variables (e.g. solar zenith angle, day length, exoatmospheric shortwave radiation), we developed the ANN model for reproducing $R_{\mathrm{Sd}}$ and further used it to upscale $\mathrm{ET}_{i}$ to $\mathrm{ET}_{\mathrm{d}}$. The efficiency of the ANN is evaluated for different morning and afternoon times of day, under varying sky conditions, and also at different geo-
\end{abstract}

graphic locations. $R_{\mathrm{S}}$-based upscaled $\mathrm{ET}_{\mathrm{d}}$ produced a significant linear relation $\left(R^{2}=0.65\right.$ to 0.69$)$, low bias $(-0.31$ to $-0.56 \mathrm{MJ} \mathrm{m}^{-2} \mathrm{~d}^{-1}$; approx. $4 \%$ ), and good agreement (RMSE 1.55 to $1.86 \mathrm{MJ} \mathrm{m}^{-2} \mathrm{~d}^{-1}$; approx. $10 \%$ ) with the observed $\mathrm{ET}_{\mathrm{d}}$, although a systematic overestimation of $\mathrm{ET}_{\mathrm{d}}$ was also noted under persistent cloudy sky conditions. Inclusion of soil moisture and rainfall information in ANN training reduced the systematic overestimation tendency in predominantly overcast days. An intercomparison with existing upscaling method at daily, 8-day, monthly, and yearly temporal resolution revealed a robust performance of the ANNdriven $R_{\mathrm{S}}$-based $\mathrm{ET}_{i}$ upscaling method and was found to produce lowest RMSE under cloudy conditions. Sensitivity analysis revealed variable sensitivity of the method to biome selection and high $\mathrm{ET}_{\mathrm{d}}$ prediction errors in forest ecosystems are primarily associated with greater rainfall and cloudiness. The overall methodology appears to be promising and has substantial potential for upscaling $\mathrm{ET}_{i}$ to $\mathrm{ET}_{\mathrm{d}}$ for field and regional-scale evapotranspiration mapping studies using polar orbiting satellites. 


\section{Introduction}

Satellite-based mapping and monitoring of daily regional evapotranspiration (ET hereafter; or latent heat flux, $\lambda E$ ) is considered to be a key scientific concern for multitudes of applications including drought monitoring, water rights management, ecosystem water-use efficiency assessment, distributed hydrological modelling, climate change studies, and numerical weather prediction (Anderson et al., 2015; Senay et al., 2015; Sepulcre-Canto et al., 2014). ET variability during the course of a day is influenced by changes in the radiative energy being received at the surface (Brutsaert and Sugita, 1992; Crago, 1996; Parlange and Katul, 1992), due to soil moisture variability, particularly in the water deficit landscapes, and also due to the stomatal regulation by vegetation.

One of the fundamental challenges in regional ET modelling using polar orbiting satellites involves the upscaling of instantaneous ET retrieved at any specific time-of-day $\left(\mathrm{ET}_{i}\right.$ hereafter) to daily ET (ET $\mathrm{ET}_{\mathrm{d}}$ hereafter). For example, $\mathrm{ET}_{i}$ retrieved from LANDSAT, ASTER and MODIS sensors typically represent $\mathrm{ET}_{i}$ at a single snapshot of 10:00, 10:30 and 13:30 LT, which needs to be upscaled to daily timescale for making this information usable to hydrologists and water managers (Cammalleri et al., 2014; Colaizzi et al., 2006; Ryu et al., 2012; Tang et al., 2013).

In order to accommodate the temporal scaling challenges encountered by remote-sensing-based ET models, techniques have been proposed and applied by various researchers to upscale $\mathrm{ET}_{i}$ to $\mathrm{ET}_{\mathrm{d}}$. These include: (1) the constant evaporative fraction (EF) approach which assumes a constant ratio between $\lambda E$ and net available energy $(\phi=$ $R_{\mathrm{n}}-G, R_{\mathrm{n}}$ is the net radiation and $G$ is the ground heat flux) during daytime $\left[\mathrm{EF}=\lambda E /\left(R_{\mathrm{n}}-G\right)\right]$ (Gentine et al., 2007; Shuttleworth et al., 1989), (2) constant reference evaporative fractions $\left(\mathrm{EF}_{\mathrm{r}}\right)$ method where the ratio of $\mathrm{ET}_{i}$ between a reference crop (typically grass measuring a height of $0.12 \mathrm{~m}$ in an environment that is not water-limited) and an actual surface is assumed to be constant during daytime, allowing $\mathrm{ET}_{\mathrm{d}}$ to be estimated from the daily $\mathrm{EF}_{\mathrm{r}}$ (Allen et al., 1998; Tang et al., 2013), (3) the constant global shortwave radiation method $\left(R_{\mathrm{S}}\right)$ where $R_{\mathrm{S}}$ is the reference variable at the land surface and it is assumed that the ratio of daily to instantaneous shortwave radiation $\left(R_{\mathrm{Sd}}\right.$ and $\left.R_{\mathrm{Si}}\right)$ values (i.e. $R_{\mathrm{Sd}} / R_{\mathrm{Si}}$ ) determines $\mathrm{ET}_{\mathrm{d}}$ to $\mathrm{ET}_{i}$ ratio (Jackson et al., 1983; Cammalleri et al., 2014), and (4) the constant extra-terrestrial radiation method where the exo-atmospheric shortwave radiation $\left(R_{\mathrm{S}} \mathrm{TOA}\right)$ is the reference variable and the ratio of instantaneous to daily $R_{\mathrm{S}} \mathrm{TOA}$ ( $R_{\mathrm{Si}} \mathrm{TOA}$ and $R_{\mathrm{Sd}} \mathrm{TOA}$ ) is assumed to determine the ratio of $\mathrm{ET}_{\mathrm{d}}$ to $\mathrm{ET}_{i}$ (Ryu et al., 2012; Van Niel et al., 2012). These methods have been reviewed and compared in different studies with the purpose of identifying the most robust $\mathrm{ET}_{i}$ to $\mathrm{ET}_{\mathrm{d}}$ upscaling approach based on different datasets, time integrals, and varying sky condi- tions (Cammalleri et al., 2014; Ryu et al., 2012; Tang et al, 2013, 2015; Van Niel et al., 2012; Xu et al., 2015).

Based on the previous studies, we find that the $R_{\mathrm{S}}$ TOA approach performed consistently well at lower temporal resolution, namely 8-day to monthly scales (Ryu et al., 2012; Van Niel et al., 2012), as well as under clear-sky conditions (Cammalleri et al., 2014), whereas the $R_{\mathrm{S}}$ approach was identified as the most preferred method for $\mathrm{ET}_{i}$ to $\mathrm{ET}_{\mathrm{d}}$ conversion at a higher temporal scale, i.e. daily timescale in addition to under variable sky conditions (Cammalleri et al., 2014; Chávez et el., 2008; Colaizzi, et al., 2006; Xu et al., 2015). Although the $\mathrm{EF}_{\mathrm{r}}$-based method produced comparable $\mathrm{ET}_{\mathrm{d}}$ estimates to the $R_{\mathrm{S}}$-based method, however the dependence of $\mathrm{EF}_{\mathrm{r}}$ estimates on certain variables (e.g. daily net available energy, $\phi$, and wind speed) and the difficulty to characterise them at the daily scale from single acquisition of polar orbiting satellites (Tang et al., 2015) makes it a relatively less attractive method. Furthermore, the EF-based method appeared to consistently underestimate $\mathrm{ET}_{\mathrm{d}}$ in all these studies.

The motivation for the current work is built on the conclusions of Colaizzi et al. (2006), Chávez et al. (2008), Cammalleri et al. (2014), and Xu et al. (2015) that the ratio of the instantaneous to daily $R_{\mathrm{S}}$ incident on land surface is the most robust reference variable explaining the ratio between $\mathrm{ET}_{\mathrm{d}}$ and $\mathrm{ET}_{i}$ among all the tested methods. This work aims to contribute to $\mathrm{ET}_{i}$ upscaling by first developing a method for estimating $R_{\mathrm{Sd}}$ from any specific time-of-day $R_{\mathrm{S}}$ information (i.e. $R_{\mathrm{Si}}$ ) and, further, using $R_{\mathrm{Sd}} / R_{\mathrm{Si}}$ ratio as a factor for converting $\mathrm{ET}_{i}$ to $\mathrm{ET}_{\mathrm{d}}$. We develop an artificial neural network (ANN) machine learning algorithm (McCulloch and Pitts, 1943) for estimating $R_{\mathrm{Sd}}$. Although net radiation $\left(R_{\mathrm{n}}\right)$ is more closely associated with ET, $R_{\mathrm{S}}$ constitutes 80$85 \%$ of $R_{\mathrm{n}}$ (Mallick et al., 2015). Also from the remotesensing perspective, $R_{\mathrm{Si}}$ is relatively easily retrievable irrespective of the sky conditions (Wang et al., 2015; Lopez and Batlles, 2014), and its relationship to $R_{\mathrm{Sd}}$ is primarily governed by cloudiness (cloud fraction, cloud optical depth) and astronomical variables (e.g. solar zenith angle, day length, $R_{\mathrm{S}} \mathrm{TOA}$ ). Given the information of cloudiness is also obtainable from remote sensing, we consider $R_{\mathrm{S}}$ to be a robust variable to explore $\mathrm{ET}_{i}$ upscaling.

Even though this study is intended for remote sensing application, we tested the method using meteorological and surface energy balance flux measurements from eddy covariance (EC) system at the FLUXNET (Baldocchi et al., 2001) sites mainly for the purpose of temporal consistency. However, we evaluate the performance in consideration with overpass time of polar orbiting satellites commonly used in operational ET mapping, namely MODIS and LANDSAT. By choosing to use data distributed over different ecosystems and climate zones, we are faced with two problems: (1) changing cloud conditions across ecosystems and (2) varying energy balance closure (EBC) requirements for the fluxes in different ecosystems (Foken et al., 2006; Franssen et al., 2010; Mauder and Foken, 2006; Wilson et 
al., 2002). Currently, information on cloudiness is obtainable from geostationary meteorological satellites, at hourly to $3 \mathrm{~h}$ time steps, e.g. from the Clouds and Earth's Radiant Energy System (CERES), the International Satellite Cloud Climatology Project-Flux Data (ISCCP-FD), and Global Energy and Water cycle Experiment Surface Radiation Budget (GEWEX-SRB). The CERES algorithm uses cloud information from MODIS onboard both Terra and Aqua platforms and combines it with information from geostationary satellites to accurately capture the diurnal cycles of clouds. In this study, cloudiness is not included in the list of variables used to estimate $R_{\mathrm{Sd}}$ due to inconsistency in spatial resolution of data to match with the other predictive variables used. Including cloudiness holds great potential for improving the ANN $R_{\mathrm{Sd}}$ predictions due to their direct relationship (Mallick et al., 2015). However, we assess the performance of the ANN under cloudy sky conditions based on simple cloudiness index computations as adopted from previous works (Baigorria et al., 2004). The EBC problems have been reported to vary across landscapes due to management practices, climate, seasons, and plant functional type characteristics (Foken et al., 2006). In this study, in order to test the robustness of the proposed method, we initially disregard the sitespecific EBC problems and assumed that the systematic bias of fluxes fall within the same range across entire FLUXNET database used.

The objectives of the present study are: (1) using a ANN with Multilayer Perceptron (MLP) architecture to predict $R_{\mathrm{Sd}}$ based on $R_{\mathrm{Si}}$ satellite observations, (2) applying the $R_{\mathrm{Sd}} / R_{\mathrm{Si}}$ ratio as a scaling factor to upscale $\mathrm{ET}_{i}$ to $\mathrm{ET}_{\mathrm{d}}$ under all sky conditions, and (3) comparing the performance of the proposed $R_{\mathrm{S}}$-based $\mathrm{ET}_{i}$ upscaling method with $R_{\mathrm{S}} \mathrm{TOA}$ and EF-based $\mathrm{ET}_{i}$ upscaling methods across a range of temporal scales, biomes, and variable sky conditions.

\section{Methodology}

\subsection{Rationale}

The presented method of ET upscaling from any specific time-of-day to daily average evaporative fluxes is based on the assumption of self-preservation of incoming solar energy (i.e. shortwave radiation) as proposed by Jackson et al. (1983).

$\mathrm{ET}_{\mathrm{d}} \approx \mathrm{ET}_{i} \frac{R_{\mathrm{Sd}}}{R_{\mathrm{Si}}}$,

where $\mathrm{ET}_{\mathrm{d}}$ is the daily average evapotranspiration in $\mathrm{W} \mathrm{m}^{-2}$, $\mathrm{ET}_{i}$ is the instantaneous evapotranspiration at any instance during daytime in $\mathrm{W} \mathrm{m}^{-2}, R_{\mathrm{Si}}$ and $R_{\mathrm{Sd}}$ are the values of shortwave radiation recorded at any instance and the daily average having units $\mathrm{W} \mathrm{m}^{-2}$. Daily total $\mathrm{ET}_{\mathrm{d}}$ and $R_{\mathrm{Sd}}$ is expressed in $\mathrm{MJ} \mathrm{m}^{-2} \mathrm{~d}^{-1}$ by using standard conversion from watts to mega joules. Following Jackson et al. (1983) and

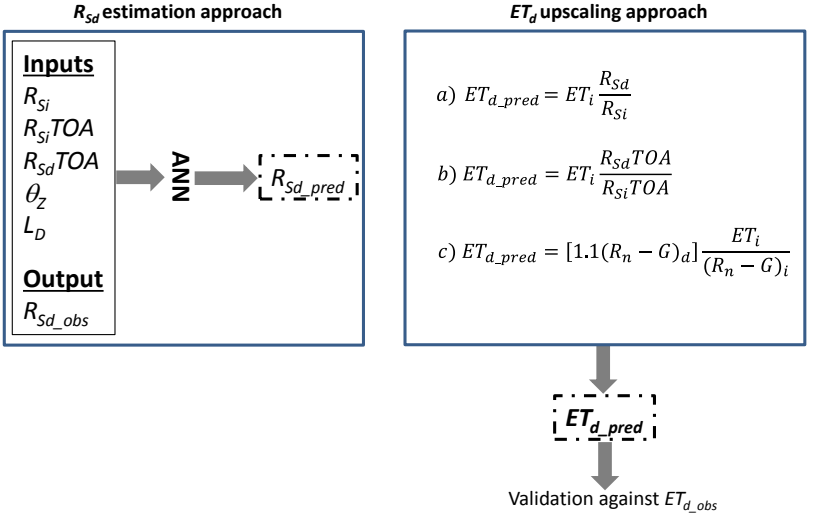

Figure 1. A conceptual diagram of the methodology. On the left side is a representation of predicting daily incoming shortwave radiation $\left(R_{\text {Sd_pred }}\right)$. The ANN is trained to learn the system response to a combination of explanatory variables (i.e. instantaneous incoming shortwave radiation $\left(R_{\mathrm{Si}}\right)$, instantaneous exo-atmospheric shortwave radiation $\left(R_{\mathrm{Si}} \mathrm{TOA}\right)$, daily exo-atmospheric shortwave radiation $\left(R_{\mathrm{Sd}} \mathrm{TOA}\right)$, solar zenith angle $\left(\theta_{\mathrm{Z}}\right)$, and day length $\left.\left(L_{\mathrm{D}}\right)\right)$ by being fed with a sample data of observed daily incoming shortwave radiation $\left(R_{\mathrm{Sd} \_ \text {obs }}\right)$ which is the dependant variable. On the right side are methods of upscaling instantaneous $\left(\mathrm{ET}_{i}\right)$ to daily ET $\left(\mathrm{ET}_{\mathrm{d}}\right)$ using our $R_{\mathrm{S}}$-based method (a) and the other two approaches $(\mathbf{b}, \mathbf{c})$ are the $R_{\mathrm{STOA}}$ - and EF-based methods respectively, which are used for comparison of $R_{\mathrm{S}}$-based method.

Cammalleri et al. (2014), we hypothesised that the mean diurnal variation of ET for any particular day scales with the mean diurnal variation of $R_{\mathrm{S}}$. The justifications are: (a) $R_{\mathrm{S}}$ is the principal driver that controls sub-daily ET variability unless there is substantial diurnal asymmetry in cloudiness or abrupt change in sub-daily soil moisture between morning and afternoon. (b) Under persistent cloudy conditions, ET scales with $R_{\mathrm{S}}$. Under clear-sky conditions ET also scales with $R_{\mathrm{S}}$ and both are in phase if sufficient soil moisture is available at the surface. (c) Phase difference between $R_{\mathrm{S}}$ and ET is commonly found under soil moisture deficit conditions in clear-sky days. However, the magnitude of clear-sky $\mathrm{ET}_{i}$ in water deficit conditions is also very low, which will lead to substantially low $\mathrm{ET}_{i} / R_{\mathrm{Si}}$ ratio, and would be unlikely to introduce any uncertainty in $\mathrm{ET}_{i}$ to $\mathrm{ET}_{\mathrm{d}}$ upscaling in the framework of Eq. (1).

For any remote sensing studies using polar orbiting satellites, although the retrieval of $\mathrm{ET}_{i}$ and $R_{\mathrm{Si}}$ has been standardised (Tang et al., 2015; Huang et al., 2012; Polo et al., 2008; Laine et al., 1999), but estimating $R_{\mathrm{Sd}}$ and $\mathrm{ET}_{\mathrm{d}}$ from $R_{\mathrm{Si}}$ and $\mathrm{ET}_{i}$ are still challenging. Presently, upscaling $R_{\mathrm{Si}}$ to $R_{\mathrm{Sd}}$ is primarily based on the clear-sky assumption, i.e. for the entire daytime integration period, the sky remains cloud-free (Bisht et al., 2005; Jackson et al., 1983). However, the clear-sky assumption is not always appropriate for upscaling remote-sensing-based $R_{\mathrm{Si}}$ and hence $\mathrm{ET}_{i}$ because the sky conditions during a specific time-of-day may be clear 


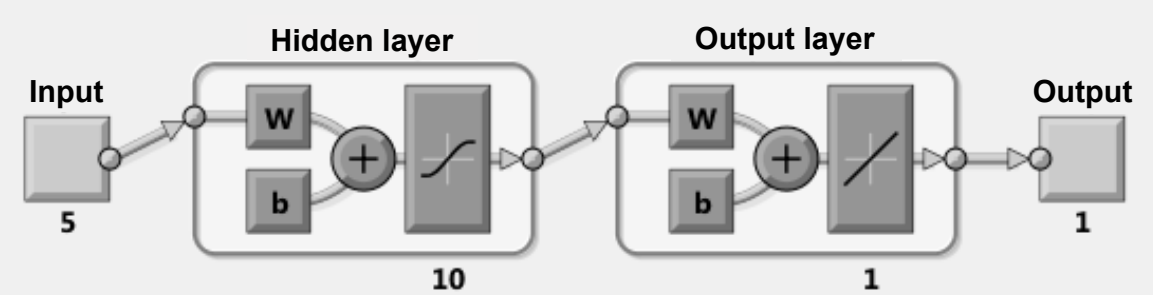

Figure 2. Schematic representation of a simple artificial network model. The artificial neuron has five input variables, for the intended output. These inputs are then assigned weights $(w)$ and bias $(b)$, and the sum of all these products $\left(\sum\right)$ is fed to an activation function $(f)$. The activation function alters the signal accordingly and passes the signal to the next neuron(s) until the output of the model is reached (Mathworks, 2015).

whereas it might be cloudy for the other part of the day. Under such conditions, the clear-sky assumption of $\mathrm{ET}_{i}$ upscaling will lead to substantial overestimation of $\mathrm{ET}_{\mathrm{d}}$. Hence reliable estimates of all-sky (i.e. both clear and cloudy) $R_{\mathrm{Sd}}$ would greatly improve the $\mathrm{ET}_{\mathrm{d}}$ estimates in the framework of Eq. (1). Given the unavailability of a definite method to directly estimate all-sky $R_{\mathrm{Sd}}$ from $R_{\mathrm{Si}}$ information, here we proposed a simple method to upscale $R_{\mathrm{Si}}$ to $R_{\mathrm{Sd}}$ using ANN. This method uses the observations of both $R_{\mathrm{Sd}}$ and $R_{\mathrm{Si}}$ from all the available FLUXNET sites in conjunction with some ancillary variables to build the ANN as described in Sect. 2.2. A schematic diagram of the ANN method is given in Fig. 1. The analysis is based on a $24 \mathrm{~h}$ period, meaning night-time ET contribution is implicitly considered. However, studies have already shown that the night-time ET in semi-arid and sub-humid regions contributes only $2-5 \%$ of the total season ET (Malek, 1992; Tolk et al., 2006), and therefore does not appear to be significant.

The overarching aim of this study is to develop an approach that would help in the upscaling of $\mathrm{ET}_{i}$ (retrieved at satellite overpass time) to $\mathrm{ET}_{\mathrm{d}}$. An additional value of this study also consists of exploiting $R_{\mathrm{Si}}$ information at satellite local crossing time to predict $R_{\mathrm{Sd}}$ which is not directly retrievable from any polar orbiting satellites, so that the ratio of $R_{\mathrm{Sd}} / R_{\mathrm{Si}}$ can be further used to upscale $\mathrm{ET}_{i}$ to obtain $\mathrm{ET}_{\mathrm{d}}$ estimates. Currently we are limited to demonstrating with MODIS satellite overpass times (Terra and Aqua); however for the future missions with different local overpass time, the method would still be applicable.

In any natural ecosystem, $R_{\mathrm{S}}$ on a particular day is primarily influenced by the clouds (especially cloud cover fraction and optical thickness; Mallick et al., 2015; Hildebrandt et al., 2007), latitude, season, and time of day. Therefore, $R_{\mathrm{Sd}}$ on any specific day is expected to be a function of $R_{\mathrm{Si}}$ (as a representative of $R_{\mathrm{S}}$ and cloudiness factors), solar zenith angle (representing latitude, season, time of day), day length (representing latitude and season), and $R_{\mathrm{S}} \mathrm{TOA}$ (representing latitude, season, and time of day). Besides, atmospheric aerosols also interact with $R_{\mathrm{S}}$ and absorb some of the radiation, particularly in the urban areas. Considering the applica- tions of $\mathrm{ET}_{i}$ to $\mathrm{ET}_{\mathrm{d}}$ modelling in the natural ecosystems, we include $R_{\mathrm{Si}}, R_{\mathrm{Si}} \mathrm{TOA}, R_{\mathrm{Sd}} \mathrm{TOA}$, solar zenith angle, and day length for $R_{\mathrm{Sd}}$ (and subsequently $\mathrm{ET}_{\mathrm{d}}$ ) prediction.

\subsection{Development of the Artificial Neural Network (ANN)}

ANN is a non-linear model which works by initially understanding the behaviour of a system based on a combination of a given number of inputs, and subsequently is able to simulate the system when fed with an independent set of inputs of the same system. ANN approach has been successfully used in estimating global solar radiation in many sectors and more so in the field of renewable energy (Ahmad et al., 2015; Hasni et al., 2012; Lazzús et al., 2011). Multi-layer perceptron (MLP) is one of the ANN architectures commonly used as opposed to other statistical methods; it makes no prior assumptions concerning the data distribution and has the ability to reasonably handle non-linear functions and reliably generalise independent data when presented (Gardner and Dorling, 1998; Khatib et al., 2012; Wang, 2003). In the present study, MLP was chosen as it has been widely used in many similar studies and cited to be a better alternative compared to the conventional statistical methods (Ahmad et al., 2015; Chen et al., 2013; Dahmani et al., 2016; Mubiru and Banda, 2008). The MLP is composed of 5 neurons in the input layer, 1 output layer and 10 hidden layers (Fig. 2). The input layer neurons are made up of instantaneous incoming shortwave radiation $\left(R_{\mathrm{Si}}\right)$, instantaneous exo-atmospheric shortwave radiation $\left(R_{\mathrm{Si}} \mathrm{TOA}\right)$, daily exo-atmospheric shortwave radiation $\left(R_{\mathrm{Sd}} \mathrm{TOA}\right)$, solar zenith angle $\left(\theta_{\mathrm{Z}}\right)$, and day length $\left(L_{\mathrm{D}}\right)$ as the predictor variables whose values are initially standardised to range between -1 and 1 . The choice of the inputs is intentionally limited to the variables that cannot only be acquired by measurements from meteorological stations but are also derived from simple astronomical computations (Ryu et al., 2012), mainly to help minimise the spatial distribution problem complexities (as described earlier in the introduction) that is often linked to ground weather stations. In the MLP processing, the input layer directs the values of each input 


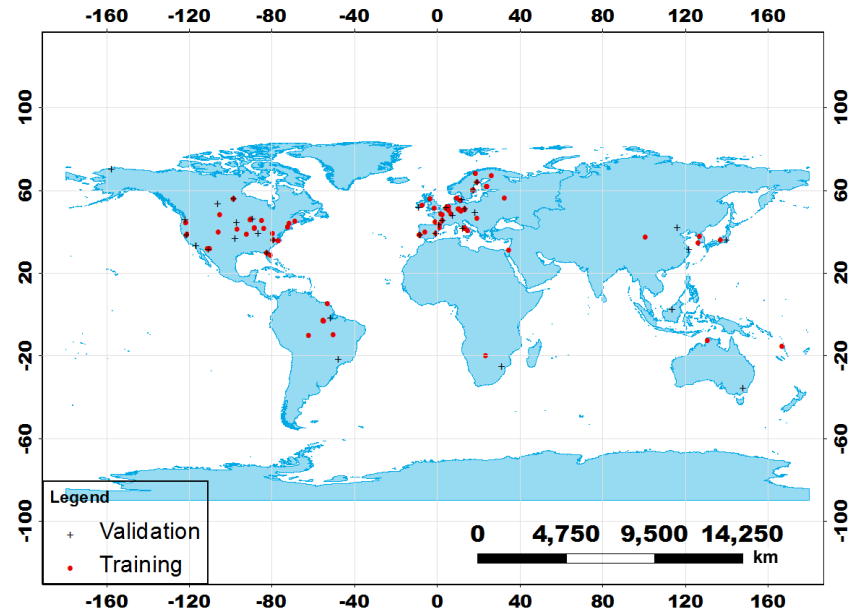

Figure 3. Distribution of 126 sites of the FLUXNET eddy covariance network used in the present study with 85 and 41 sites for training and validation between the years 1999 and 2006, respectively.

neuron $x_{i}(i=1,2,3 \ldots n)$ into each neuron $(j)$ of the hidden layers. In the hidden layer, $x_{i}$ is multiplied by a weight $\left(w_{i j}\right)$ followed by a bias $\left(b_{j}\right)$ assigned for each hidden layer. The weighted sum (Eq. 2) is fed into a transfer function. In this work a tangent sigmoid (TANSIG) function is used (Eq. 3) in the hidden layer while in the output layer a PURELIN function is applied (Eq. 4) to give a single output value which is the predicted daily shortwave radiation $\left(R_{\text {Sd pred }}\right)$. PURELIN is a linear neural transfer function used in a backpropagation network. It calculates a layer's output from its net input. The function generates outputs between zero and 1 as the neuron's net input goes from negative to positive infinity. The training of the ANN is completed by a regression analysis being performed internally by the algorithm between the target variable, i.e. the observed and predicted daily shortwave radiation $\left(R_{\text {Sd_pred }}\right.$ and $\left.R_{\text {Sd_pred }}\right)$.

$$
\begin{aligned}
X_{j} & =\int\left(\sum_{j=1}^{n} w_{i j} y_{j} b_{j}\right) \\
y_{j} & =\frac{2}{\left(1+\exp \left(-2 X_{j}\right)-1\right)} \\
y_{j} & =X_{j}(\text { PURELIN })
\end{aligned}
$$

The Bayesian regularisation algorithm was chosen for the optimisation process because it is able to handle noisy datasets by continuously applying adaptive weight minimisation, and can reduce or eliminate the need for lengthy cross-validation that often leads to overtraining and overfitting of models (Burden and Winkler, 2009).

\subsection{Datasets}

Daily and half-hourly data on $R_{\mathrm{S}}\left(\mathrm{W} \mathrm{m}^{-2}\right), R_{\mathrm{STOA}}$, net radiation $\left(R_{\mathrm{n}}, \mathrm{W} \mathrm{m}^{-2}\right)$, latent heat flux $\left(\lambda E, \mathrm{~W} \mathrm{~m}^{-2}\right)$, sensible heat flux $\left(H, \mathrm{~W} \mathrm{~m}^{-2}\right)$, and ground heat flux $\left(G, \mathrm{~W} \mathrm{~m}^{-2}\right)$ measured by the FLUXNET (Baldocchi et al., 2001) eddy covariance network were used. A total of 126 sites from the years 1999 to 2006 , distributed between latitude $0-90^{\circ}$ north and south of the Equator, were used for the present analysis. The data sites covered a broad spectrum of vegetation functional types and climatic conditions and a list of the sites are given in Table S1 in the Supplement.

Among 126 sites, 85 sites were used for training and the remaining 41 sites were used for validation. Partition of the data into training and validation was randomly selected regardless of the year. These translated into 194 and 86 yearly data for the respective samples. A global distribution of the data sites is shown in Fig. 3. From the training dataset, three samples were internally generated by the algorithm, i.e. training datasets, validation datasets, and a testing dataset in a percentage ratio of $80: 15: 5$ respectively. The ANN algorithm is designed to validate its performance for any given training which in most cases should be sufficient for validating the network. However, to ensure the network is robust, we further test the generated network with an independent dataset. Considering the equatorial crossing time of different polar orbiting sensors like LANDSAT, ASTER, and MODIS TerraAqua, unique networks were generated for different time of day from morning to afternoon, and thus we had a total of eight networks to represent potential satellite overpass times between 10:30 and 14:00 LT using $30 \mathrm{~min}$ intervals as the closest reference time for each hour. The generated networks were then applied to an independent validation dataset.

\subsection{Intercomparison of ET $_{i}$ upscaling methods}

An intercomparison of three different $\mathrm{ET}_{i}$ upscaling methods is performed with the homogeneous datasets to assess their relative performance across a range of temporal scales and variable sky conditions. These are:

a. The $R_{\mathrm{S}}$-based upscaling method, where ANN-predicted $R_{\mathrm{Sd}}$ is used in conjunction with observed $R_{\mathrm{Si}}$ to predict $\mathrm{ET}_{\mathrm{d}}$ using Eq. (1).

b. The exo-atmospheric irradiance method (Ryu et al., 2012) where the reference variable is $R_{\mathrm{S}}$ TOA.

$$
\begin{aligned}
R_{\mathrm{Sd}} \mathrm{TOA} & =S_{\mathrm{Sc}}\left[1+0.033 \cos \left(\frac{2 \pi t_{d}}{365}\right)\right] \cos \theta_{\mathrm{Z}}, \\
\mathrm{SF}_{\mathrm{RTOA}} & =\frac{R_{\mathrm{Sd}} \mathrm{TOA}}{R_{\mathrm{Si}} \mathrm{TOA}}, \\
\mathrm{ET}_{\mathrm{d}} & =\mathrm{ET}_{i} \mathrm{SF}_{\mathrm{RTOA}},
\end{aligned}
$$

where $S_{\mathrm{sc}}$ is the solar constant $\left(1360 \mathrm{~W} \mathrm{~m}^{-2}\right), t_{d}$ is the day of the year (DoY), and $\theta_{Z}$ is the solar zenith angle. 
b. The EF-based method (Cammalleri et al., 2014), where the reference variable is the net available energy $(\phi$; i.e. $\left.R_{\mathrm{n}}-G\right)$.

$$
\begin{aligned}
\mathrm{SF}_{\mathrm{EF}} & =\frac{\mathrm{ET}_{i}}{\left(R_{n}-G\right)_{i}}, \\
\mathrm{ET}_{\mathrm{d}} & =1.1\left(R_{\mathrm{n}}-G\right)_{\mathrm{d}} \mathrm{SF}_{\mathrm{EF}},
\end{aligned}
$$

where $\mathrm{SF}_{\mathrm{EF}}$ is the EF-based scaling factor, $\left(R_{\mathrm{n}}-G\right)_{i}$ and $\left(R_{\mathrm{n}}-\right.$ $G)_{\mathrm{d}}$ are the instantaneous and daily net available energy, respectively.

We tested the performance of the three upscaling algorithms for all possible sky conditions assumed to be represented by daily atmospheric transmissivity ( $\tau$; Eq. 10), namely (i) $0.25 \geq \tau \geq 0$ ( $\tau_{1}$, hereafter), (ii) $0.5 \geq \tau \geq 0.25$ ( $\tau_{2}$, hereafter) (iii) $0.75 \geq \tau \geq 0.5$ ( $\tau_{3}$, hereafter), and (iv) $1 \geq$ $\tau \geq 0.75$ ( $\tau_{4}$, hereafter). We use daily $\tau$ because it indicates the overall sky condition throughout a day.

$$
\tau=\frac{R_{\mathrm{Sd}}}{R_{\mathrm{Sd}} \mathrm{TOA}}
$$

$R_{\mathrm{Sd}}$ and $R_{\mathrm{Sd}} \mathrm{TOA}$ are daily shortwave radiation and the exo-atmospheric shortwave radiation, respectively, in $\mathrm{MJ} \mathrm{m}^{-2} \mathrm{~d}^{-1}$ (converted from $\mathrm{W} \mathrm{m}^{-2}$ ).

\subsection{Statistical error analysis}

The relative performance of the ANN and three upscaling methods is evaluated using some statistical indices, namely: coefficient of determination $\left(R^{2}\right)$, root mean square error (RMSE), mean absolute percentage error (MAPE), index of agreement (IA), and bias. $\mathrm{ET}_{\mathrm{d}}$ estimates using the respective upscaling coefficients were compared with measured $\mathrm{ET}_{\mathrm{d}}$.

$$
\begin{aligned}
R^{2} & =1-\frac{\sum_{i=1}^{n}\left(p_{i}-o_{i}\right)^{2}}{\sum_{i=1}^{n}\left(o_{i}\right)^{2}}, \\
\mathrm{RMSE} & =\sqrt{\frac{\sum_{i=1}^{n}\left(o_{i}-p_{i}\right)^{2}}{n},} \\
\mathrm{MAPE} & =\frac{1}{n} \sum_{i=1}^{n} \frac{\left|o_{i}-p_{i}\right|}{n} \times 100, \\
\mathrm{IA} & =\frac{\sum_{i}^{n}\left(p_{i}-o_{i}\right)^{2}}{\sum_{i=1}^{n}\left(\left|p_{i}-o_{i}\right|+\left|o_{i}-p_{i}\right|\right)^{2}}, \\
\operatorname{Bias} & =\frac{\sum_{i=1}^{n}\left(p_{i}-o_{i}\right)}{n},
\end{aligned}
$$

where $n$ is the number of data points; $o_{i}$ and $p_{i}$ are daily observed and estimated $R_{\mathrm{Sd}}$ or $\mathrm{ET}_{\mathrm{d}}$, respectively. $\bar{O}$ was the mean value of observed $R_{\mathrm{Sd}}$ or $\mathrm{ET}_{\mathrm{d}}$.

\subsection{Sensitivity of ANN training and validation}

Given the majority of the FLUXNET sites represent forest biomes and the distribution of EC sites over non-forest biomes are proportionately lower compared to the forests, we performed a sensitivity analysis of the ANN-based approach by assessing the error statistics ( $R^{2}$ and RMSE) of predicted $\mathrm{ET}_{\mathrm{d}}$ for different scenarios of ANN training. Three case studies were generated: (a) Case1, where ANN was trained by including data randomly from the forests and $\mathrm{ET}_{\mathrm{d}}$ validation was done in non-forest biomes (i.e. grassland, crops, and shrublands); (b) Case2, where ANN was trained by including data randomly from the non-forest biomes and predicted $\mathrm{ET}_{\mathrm{d}}$ was evaluated in forest biome; (c) Case3, where ANN was trained by using data randomly from equal proportions of forest and non-forest biomes, and $\mathrm{ET}_{\mathrm{d}}$ validation was also done in forest and non-forest biomes. Each individual case was replicated 10 times and an ensemble of mean statistics of predicted $\mathrm{ET}_{\mathrm{d}}$ is reported in Sect. 3.5.

\section{Results and discussions}

\subsection{Testing the performance of predicted $R_{\mathrm{Sd}}$}

Given that the performance of $\mathrm{ET}_{\mathrm{d}}$ upscaling depends on the soundness of $R_{\mathrm{Sd}}$ estimation, we first evaluate the efficacy of the ANN method for predicting $R_{\mathrm{sd}}$. Figure 4 summarises the statistical results of predicted $R_{\mathrm{Sd}}\left(R_{\mathrm{Sd} \_ \text {pred }}\right.$, hereafter) including all the site-year average $R^{2}$, RMSE, IA, and MAPE values for eight different time-of-day upscaling time slots. The RMSE of $R_{\text {Sd_pred }}$ from morning upscaling varied between 1.81 and $1.85 \mathrm{MJ} \mathrm{m}^{-2} \mathrm{~d}^{-1}$, with MAPE, $R^{2}$, and IA varying across the ranges $20-21 \%, 0.76-0.77$, and $0.79-0.80$, respectively (Fig. 4). For the afternoon, these statistics were almost similar and varied across the ranges $1.83-1.96 \mathrm{MJ} \mathrm{m}^{-2} \mathrm{~d}^{-1}, 19-20 \%, 0.75-0.77$, and $0.80-0.81$ (Fig. 4). Given the minimal discrepancy in error statistics from both morning and afternoon integration and taking into account the MODIS Terra-Aqua average overpass time, we have considered 11:00 and 13:30 LT for the detailed followup analysis.

Figure $5 \mathrm{a}$ and $\mathrm{b}$ evaluates $R_{\text {Sd_pred }}$ statistics under different levels of atmospheric transmissivity $(\tau ; 0.25 \geq \tau \geq 0,0.5 \geq$ $\tau \geq 0.25,0.75 \geq \tau \geq 0.5$, and $1 \geq \tau \geq 0.75$ ) with an overall RMSE of 1.81 and $1.83 \mathrm{MJ} \mathrm{m}^{-2} \mathrm{~d}^{-1}$ for the morning and afternoon upscaling respectively. Table 1 and Fig. 5 clearly show an overestimation tendency of the current method under persistent cloudy sky conditions $\left(\tau_{1}\right)$, whereas the predictive capacity of the ANN model is reasonably strong with increasing atmospheric clearness. The RMSE of $R_{\text {Sd_pred }}$ for different $\tau$ class from morning upscaling varied between 0.62 and $2.45 \mathrm{MJ} \mathrm{m}^{-2} \mathrm{~d}^{-1}$, with MAPE, $R^{2}$, and IA of 9.2 to $53 \%, 0.67$ to 0.98 , and 0.67 to 0.95 , respectively (Table 1). For the afternoon upscaling these statistics were 0.89 to $2.4 \mathrm{MJ} \mathrm{m}^{-2} \mathrm{~d}^{-1}$ (RMSE), 2.4 to $52 \%$ (MAPE), 0.65 to $0.98\left(R^{2}\right)$, and 0.67 to 0.95 (IA; Table 1 ).

The overestimation of $R_{\text {Sd_pred }}$ at low values of $\tau$ is presumably associated with varying levels of cloudiness during 
Table 1. Statistical analysis of the performance of ANN in predicting $R_{\mathrm{Sd}}$ under varying sky conditions represented by four different classes of daily atmospheric transmissivity $(\tau)$. Here the statistical metrics of $R_{\text {Sd_pred }}$ for two different upscaling hours (11:00 and 13:30LT) are presented.

\begin{tabular}{lccrrrr}
\hline $\begin{array}{l}\text { Time of day } \\
\text { (LT) }\end{array}$ & $\tau$ & $R^{2}$ & $\begin{array}{r}\text { RMSE } \\
\left(\mathrm{MJ} \mathrm{m}^{-2} \mathrm{~d}^{-1}\right)\end{array}$ & IA & $\begin{array}{r}\text { MAPE } \\
(\%)\end{array}$ & $\begin{array}{r}\text { Bias } \\
\left(\mathrm{MJ} \mathrm{m}^{-2} \mathrm{~d}^{-1}\right)\end{array}$ \\
\hline $11: 00$ & $\tau_{1}$ & 0.67 & 1.84 & 0.67 & 53.56 & 1.12 \\
& $\tau_{2}$ & 0.79 & 2.45 & 0.80 & 16.69 & 0.59 \\
& $\tau_{3}$ & 0.88 & 2.30 & 0.82 & 9.17 & -0.74 \\
& $\tau_{4}$ & 0.98 & 0.63 & 0.95 & 1.69 & 0.08 \\
\hline $13: 30$ & $\tau_{1}$ & 0.65 & 1.77 & 0.67 & 51.50 & 1.06 \\
& $\tau_{2}$ & 0.81 & 2.44 & 0.81 & 16.83 & 0.69 \\
& $\tau_{3}$ & 0.89 & 2.23 & 0.83 & 8.94 & -0.85 \\
& $\tau_{4}$ & 0.98 & 0.89 & 0.95 & 2.40 & -0.46 \\
\hline
\end{tabular}
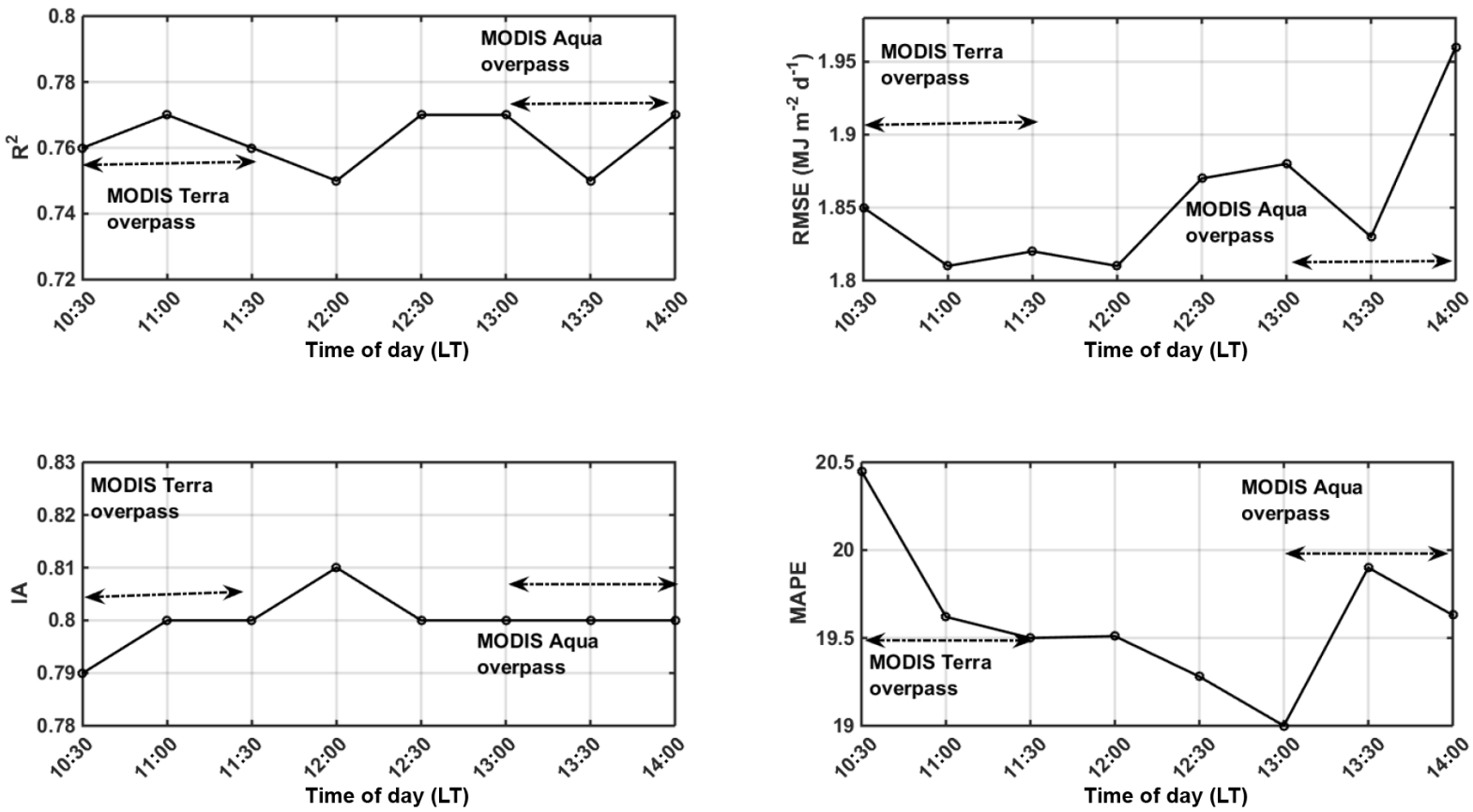

Figure 4. Statistical metric of $R_{\text {Sd_pred }}$ by ANN for different times of day. As the study is intended for remote sensing application, we demonstrate the potential of the method for future research in the case where the satellite will be used, and as such we pick MODIS overpass time as an example to highlight the predictive ability of the ANN at the specific overpass times.

the daytime. Since $R_{\mathrm{Sd} \text { pred }}$ depends on the magnitude of $R_{\mathrm{Si}}$, $L_{\mathrm{D}}, \theta_{\mathrm{Z}}, R_{\mathrm{SiTOA}}$, and $R_{\mathrm{SdTOA}}$, there will be a tendency to overestimate $R_{\mathrm{Sd} \text { _pred }}$ on partly cloudy days if $R_{\mathrm{Si}}$ at a specific time of day is not affected by the clouds $\left(L_{\mathrm{D}}, \theta_{\mathrm{Z}}, R_{\mathrm{SiTOA}}\right.$, and $R_{\text {SdTOA }}$ are not influenced by the clouds).

\subsection{Evaluation of predicted $\mathbf{E T}_{\mathbf{d}}$ based on $\boldsymbol{R}_{\text {Sd_pred }}$}

Figure 6 summarises the statistical results of predicted $\mathrm{ET}_{\mathrm{d}}$ $\left(\mathrm{ET}_{\mathrm{d} \_ \text {pred, }}\right.$ hereafter) for eight different time-of-day slots. Upon statistical evaluation, all the cases showed a significantly linear relationship between $\mathrm{ET}_{\mathrm{d} \_ \text {pred }}$ and observed
$\mathrm{ET}_{\mathrm{d}}\left(\mathrm{ET}_{\mathrm{d} \_ \text {obs }}\right.$, hereafter $)$. The RMSE of $\mathrm{ET}_{\mathrm{d} \_ \text {pred }}$ from morning upscaling varied from 1.67 to $1.84 \mathrm{MJ} \mathrm{m}^{-2} \mathrm{~d}^{-1}$, with MAPE, $R^{2}$, and IA varying across the ranges $30-34 \%$, $0.62-0.68$, and 0.77-0.80, respectively (Fig. 6). For the afternoon upscaling, these statistics varied across the ranges $1.5-1.6 \mathrm{MJ} \mathrm{m}^{-2} \mathrm{~d}^{-1}, 29-30 \%, 0.67-0.71$, and 0.80 (Fig. 6) These results also indicate that the error statistics were nearly uniform and the accuracy of $\mathrm{ET}_{\mathrm{d} \_ \text {pred }}$ varied only slightly when integration was done from different times of day between 10:30 and 14:00 LT. These typical error characteristics can greatly benefit the $\mathrm{ET}_{\mathrm{d}}$ modelling using polar orbiting data with varying overpass times between 10:30 and 
(a)

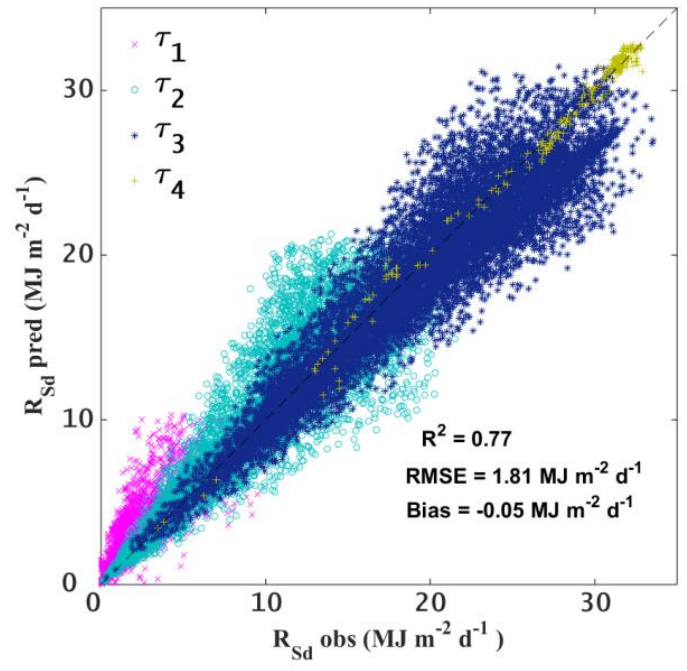

(b)

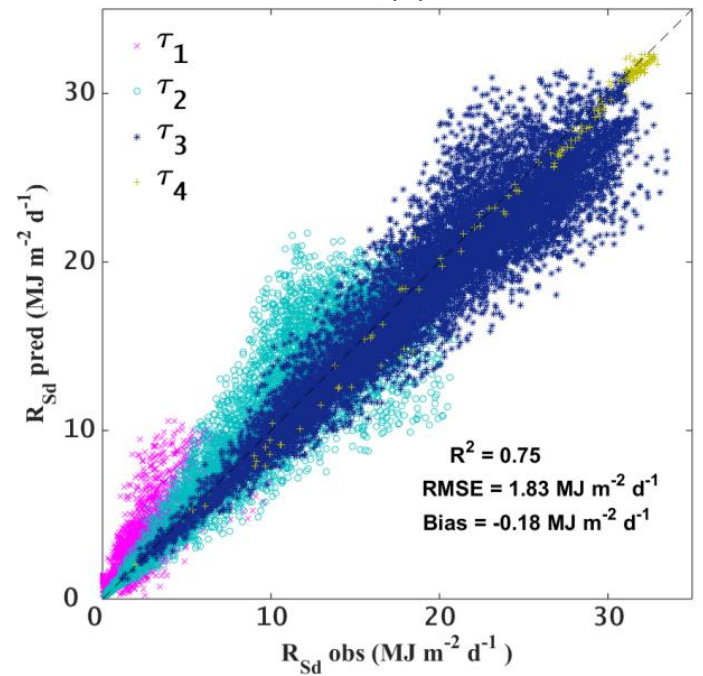

Figure 5. Scatter plots showing $R_{\text {Sd_pred }}$ vs. $R_{\text {Sd_obs }}$ for different levels of daily atmospheric transmissivity classes $(\tau)$ from (a) 11:00 to (b) 13:30 LT upscaling. Here $\tau_{1}-\tau_{4}$ represent daily atmospheric transmissivity of four different classes, $0.25 \geq \tau \geq 0,0.50 \geq \tau \geq 0.25$, $0.75 \geq \tau \geq 0.50$, and $1 \geq \tau \geq 0.75$, respectively, with $\tau_{1}$ signifying a high degree of cloudiness (or overcast skies) whereas $\tau_{4}$ indicates clear skies.
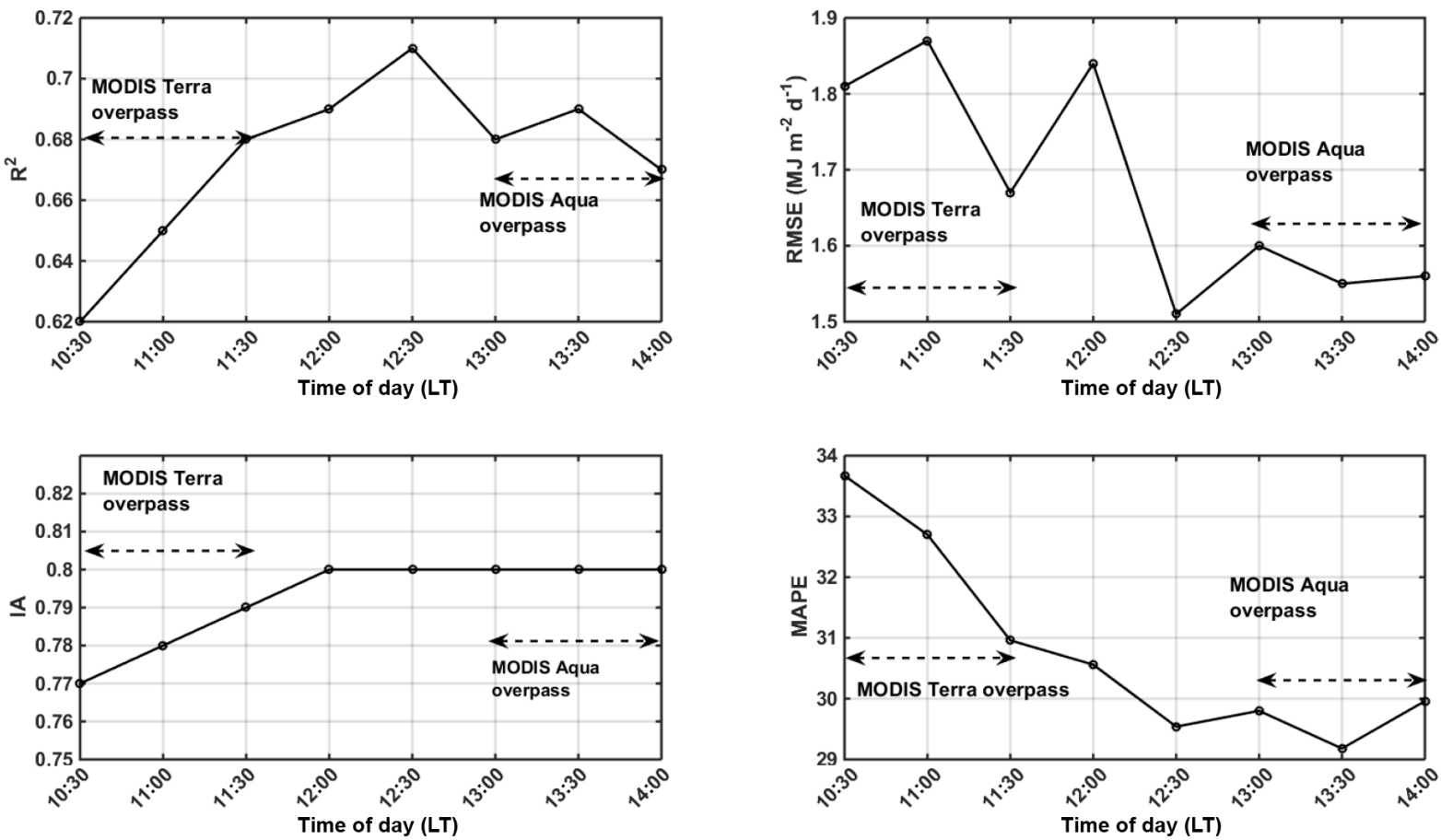

Figure 6. Statistical summary of $\mathrm{ET}_{\mathrm{d} \_ \text {pred }}$ for different times of day using Eq. (1) based on $R_{\mathrm{Si}}$ and $R_{\mathrm{Sd} \_p r e d}$. As the study is intended for remote sensing application, we once again demonstrate the potential of the method for future research in the case where satellite will be used and as such we pick MODIS Terra-Aqua overpass time.

14:00 LT. This also opens up the possibility of using either a morning satellite (e.g. MODIS Terra, LANDSAT, ASTER etc.) or afternoon satellite (i.e. MODIS Aqua) to upscale $\mathrm{ET}_{i}$ to $\mathrm{ET}_{\mathrm{d}}$. Following $R_{\mathrm{Sd}}$, here also we restricted our analysis to the two different times of day (11:00 and 13:30 LT) representing Terra and Aqua overpass times.

Figure $7 \mathrm{a}$ and $\mathrm{b}$ compares $\mathrm{ET}_{\mathrm{d} \_ \text {pred }}$ against $\mathrm{ET}_{\mathrm{d} \_ \text {obs }}$ for different levels of daily $\tau$. The overall RMSE, MAPE, and 
(a)

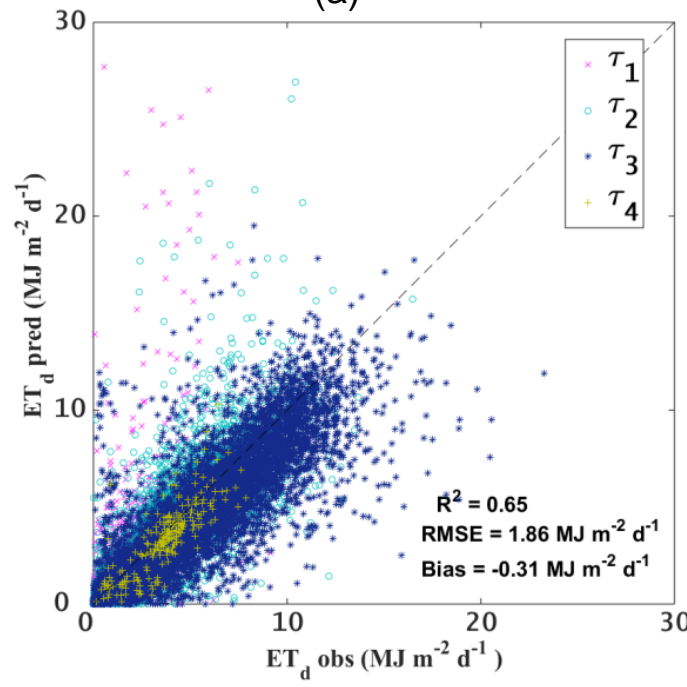

(b)

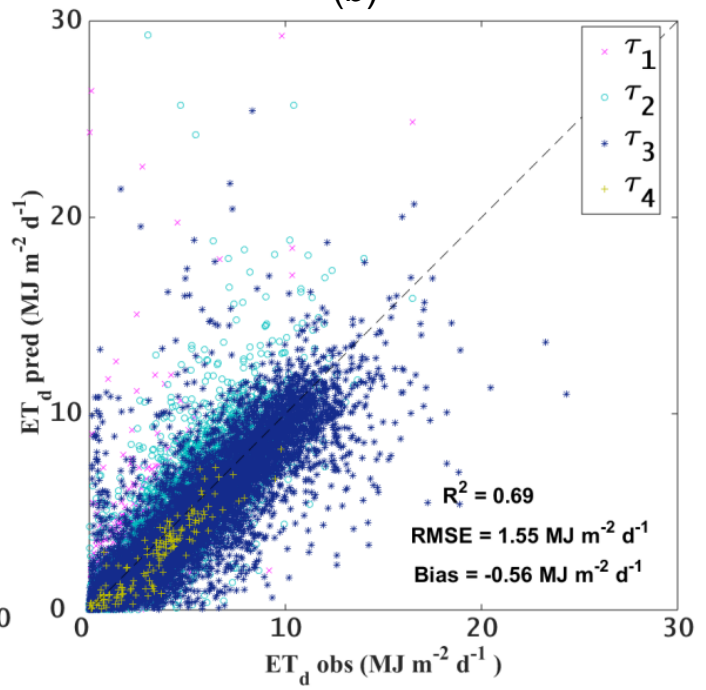

Figure 7. $\mathrm{ET}_{\mathrm{d} \_ \text {pred }}$ obtained through Eq. (1) vs. $\mathrm{ET}_{\mathrm{d} \_ \text {obs }}$ for different levels of $\tau$ from both morning (a) and afternoon (b) upscaling (11:00 and 13:30 LT).

$R^{2}$ were 1.86 and $1.55 \mathrm{MJ} \mathrm{m}^{-2} \mathrm{~d}^{-1}, 31$ and $36 \%$, and 0.65 and 0.69 for the morning and afternoon upscaling, respectively. As seen in Fig. 7, there is a systematic overestimation of $\mathrm{ET}_{\mathrm{d} \_ \text {pred }}$ relative to the tower-observed values for low range of $\tau$ (i.e. cloudy sky). It is important to realise that, unlike $\mathrm{ET}_{\mathrm{d} \_ \text {obs }}, \mathrm{ET}_{\mathrm{d} \_ \text {pred }}$ might be an outcome of $\mathrm{ET}_{i}$ instances when the sky was not overcast, i.e. the sky conditions might be clear at specific time-of-day but can be substantially overcast for the remainder of the daytime. As a result, any bias in the daily shortwave radiation prediction $\left(R_{\mathrm{Sd} \_ \text {pred }}\right)$ will result in biased $\mathrm{ET}_{\mathrm{d} \_ \text {pred }}$ according to Eq. (1), and the omission of non-clear sky conditions at any particular time of daytime would tend to lead to $\mathrm{ET}_{\mathrm{d}_{-} \text {pred }}>\mathrm{ET}_{\mathrm{d} \_ \text {obs }}$ for generally overcast days. However, there could be another opposite case that the sky is cloudy at for example 11:00 LT but clear at other times. This will probably lead to an underestimation of $R_{\text {Sd_pred }}$, and consequently underestimation of $\mathrm{ET}_{\mathrm{d} \_ \text {pred. }}$. Such cases were also found in $\tau_{3}$ categories in Fig. 7 where clouds of data points clearly falling significantly below the 1:1 line, thus showing substantial underestimation of $\mathrm{ET}_{\mathrm{d} \_ \text {pred }}$. Since $\mathrm{ET}_{\mathrm{d} \_ \text {obs }}$ are the integrations of multiple $\mathrm{ET}_{i}$ measurements, such conditions could be conveniently captured in the observations which were not possible in the current framework of $\mathrm{ET}_{\mathrm{d} \_ \text {pred. }}$. Therefore, when upscaling was done under clear skies at nominal acquisition time for generally overcast days, higher errors in $\mathrm{ET}_{\mathrm{d} \_ \text {pred }}$ can be expected (Cammalleri et al., 2014) and vice versa. We examined this cloudy sky overestimation pattern in greater detail by evaluating the error statistics in $\mathrm{ET}_{\mathrm{d} \_ \text {pred }}$ for four different levels of daily $\tau$ categories (Fig. 8).

Statistical evaluation of $\mathrm{ET}_{\mathrm{d} \_ \text {pred }}$ for different classes of daily $\tau$ (estimated as the ratio between daily observed $R_{\mathrm{Sd}}$ and $R_{\mathrm{Sd}} \mathrm{TOA}$ ) indicates the tendency of higher RMSE and low $R^{2}$ in $\mathrm{ET}_{\text {d_pred }}$ under the persistent cloudy-sky conditions $\left(\tau_{1}\right)$, while the performance of $\mathrm{ET}_{\mathrm{d}_{\mathrm{B}} \text { pred }}$ is reasonably good with increasing atmospheric clearness $\left(\tau_{2}, \tau_{3}\right.$, and $\tau_{4}$ ) (Fig. 8). The RMSE of $\mathrm{ET}_{\mathrm{d}_{-} \text {pred }}$ for different $\tau$ class from morning upscaling varied between 1.09 and $2.96 \mathrm{MJ} \mathrm{m}^{-2} \mathrm{~d}^{-1}$, with MAPE, $R^{2}$, and IA of 25 to $75 \%$, 0.38 to 0.79 , and 0.71 to 0.82 , respectively. For the afternoon upscaling, these statistics were 0.98 to $2.02 \mathrm{MJ} \mathrm{m}^{-2} \mathrm{~d}^{-1}$ (RMSE), 24 to $87 \%$ (MAPE), 0.40 to $0.68\left(R^{2}\right)$, and 0.71 to 0.77 (IA).

To probe into detail the high errors under persistent cloudiness conditions, a new ANN was trained by introducing daily precipitation $(P)$ and soil moisture (SM) information (along with $R_{\mathrm{S}}, R_{\mathrm{S}} \mathrm{TOA}, \theta_{\mathrm{Z}}$, and $L_{\mathrm{D}}$ ) assuming that the inclusion of these two variables might improve the predictive power of $R_{\mathrm{S}}$-based ANN. In the new ANN, we used data from those sites where coincident measurements of $P$ and SM were available along with $R_{\mathrm{S}}$ and ET, and validated $\mathrm{ET}_{\mathrm{d}}$ predictions of the new ANN on independent sites. The analysis revealed a $34 \%$ reduction in RMSE (from 3.28 to $2.88 \mathrm{MJ} \mathrm{m}^{-2} \mathrm{~d}^{-1}$ ), $16 \%$ reduction in MAPE (from 90 to $76 \%$ ), and $49 \%$ reduction in mean bias (from 0.76 to $0.39 \mathrm{MJ} \mathrm{m}^{-2} \mathrm{~d}^{-1}$ ) for persistent cloudy-sky cases (i.e. $\tau_{1}$ scenarios) from 11:00 LT upscaling. However, no significant improvements in $\mathrm{ET}_{\text {d_pred }}$ were evident for $\tau_{2}, \tau_{3}$, and $\tau_{4}$ or for any of the $\tau$ classes from the afternoon (13:30 LT) upscaling (Fig. 9). ET $_{d}$ is generally controlled by radiation and soil moisture availability. Under the radiation-controlled conditions, $\mathrm{ET}_{\mathrm{d}}$ is generally not limited due to soil moisture and $70-75 \%$ of the net radiation is contributed to $\mathrm{ET}_{\mathrm{d}}$. Therefore, the $R_{\mathrm{S}}$-based method of $\mathrm{ET}_{i}$ upscaling is expected to 

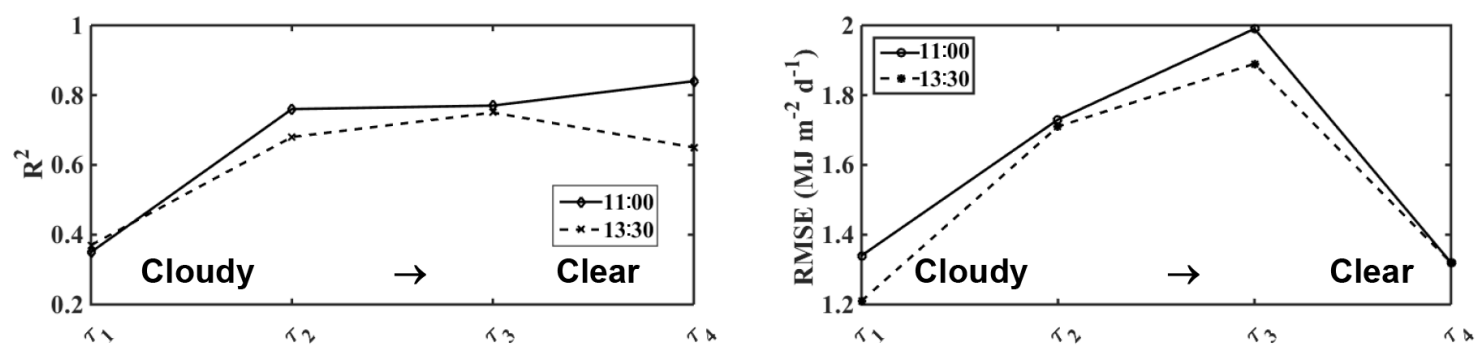

Atmospheric transmissivity $(\tau)$ classes
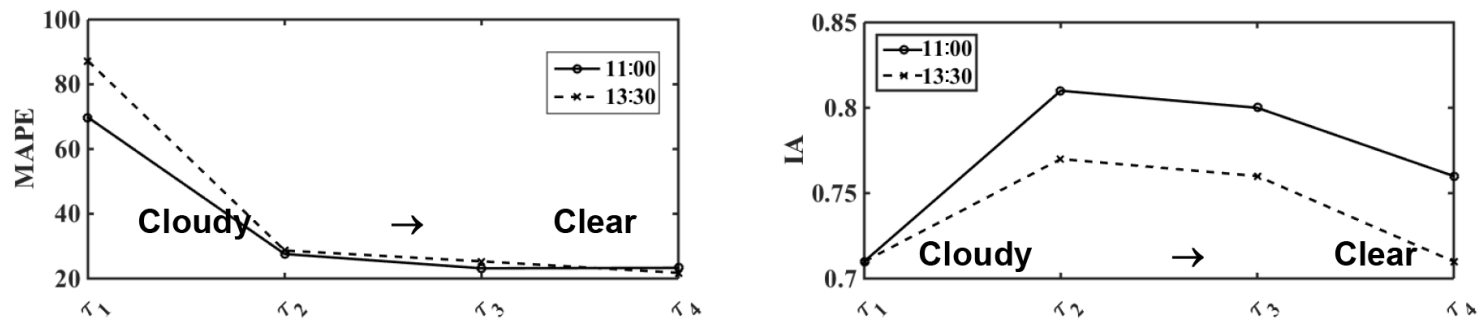

Atmospheric transmissivity $(\tau)$ classes

Figure 8. Assessing the statistical metrics of $\mathrm{ET}_{\mathrm{d} \_ \text {pred }}$ (using Eq. 1) for different levels of daily atmospheric transmissivity classes (representing cloudy to clear skies) for both 11:00 and 13:30 LT time-of-day $\mathrm{ET}_{i}$ scaling.

perform reasonably well unless the upscaling is performed from a clear-sky instance for a predominantly overcast or rainy day. However, from Fig. 9 it is apparent that the inclusion of cloud information (cloud fraction, cloud optical thickness) in $R_{\mathrm{S}}$-based ANN would substantially reduce $\mathrm{ET}_{\mathrm{d} \_ \text {pred }}$ errors when upscaling is performed from a clear sky instance for a predominantly overcast day, and vice versa. Improvements of $\mathrm{ET}_{\mathrm{d} \_ \text {pred }}$ error statistics by including daily $P$ and SM (as an indicator of cloudiness) is also suggestive of the relevance of such an approach as a future improvement of the current framework, which is expected to reduce the systematic error under overcast conditions. However, the cloud information available from alternative sources (e.g. from the Clouds and Earth's Radiant Energy System (CERES), the International Satellite Cloud Climatology Project-Flux Data (ISCCP-FD), and the Global Energy and Water cycle Experiment Surface Radiation Budget (GEWEX-SRB)) are available at coarse spatial resolution $\left(100 \mathrm{~km}^{2}\right)$. Combining this information with EC tower measurements to train ANN could also introduce additional errors due to the spatial scale mismatch, and is therefore out of scope of the present study.

Figure 10 shows the time series comparisons between observed $\mathrm{ET}_{\mathrm{d}}$ and $\mathrm{ET}_{\mathrm{d}_{\mathrm{A}} \text { pred }}$ for four different stations representing different latitude bands of both the Northern (Sweden) and Southern (Brazil, Australia, and South Africa) hemispheres. These reveal that the temporal dynamics of $\mathrm{ET}_{\mathrm{d}}$ is in general consistently captured by the proposed method throughout the year. In Br_SP1, relatively less seasonality was found in both the observed and predicted $\mathrm{ET}_{\mathrm{d}}$. This is because SP1 is a tropical site having an annual rainfall of $850-1100 \mathrm{~mm}$, most of which is evenly distributed be- tween March and the end of September. The peaks in $\mathrm{ET}_{\mathrm{d}}$ values during the beginning of the year and from October onwards coincided with the periods of increased $R_{\mathrm{S}}$, and $\mathrm{ET}_{\mathrm{d} \_ \text {pred }}$ could reasonably capture the observed trends during both rainy and non-rainy periods. Similarly the low $\mathrm{ET}_{\mathrm{d}}$ pattern (0.1 to $\left.2 \mathrm{MJ} \mathrm{m}^{-2} \mathrm{~d}^{-1}\right)$ in the hot arid climate of South Africa (Za-Kru) could also be reasonably captured in $\mathrm{ET}_{\text {d_pred }}$ (Fig. 10). $\mathrm{ET}_{\mathrm{d}_{\text {_pred }}}$ in the other Southern Hemisphere (AU-Tum) and Northern Hemisphere (SE-Fla) sites have shown distinct seasonality (high summer and low winter $\mathrm{ET}_{\mathrm{d}}$ ) coinciding with the observed $\mathrm{ET}_{\mathrm{d}}$ patterns.

\subsection{Comparison with existing ET upscaling methods}

$\mathrm{ET}_{\mathrm{d} \_ \text {pred }}$ from the $R_{\mathrm{S}}$-based method was intercompared with two other upscaling schemes $\left(R_{\mathrm{S}} \mathrm{TOA}\right.$ and $\left.\mathrm{EF}\right)$ over 41 FLUXNET validation sites for two different times of day, 11:00 and 13:30 LT, the statistics of which are given in Table 2 . This comparison was also carried out according to different $\tau$ classes as defined in Sect. 2.4.

From Table 2 it is apparent that the $R_{\mathrm{S}}$-based method has generally produced relatively low RMSE (1.21 to $1.99 \mathrm{MJ} \mathrm{m}^{-2} \mathrm{~d}^{-1}$ ) and MAPE (23 to $50 \%$ ) as well as relatively high IA ( 0.72 to 0.84 ) compared to $R_{\mathrm{S}} \mathrm{TOA}$ and EFbased upscaling methods. The EF-based upscaling method appears to systematically underestimate $\mathrm{ET}_{\mathrm{d}}$ for both morning and afternoon as evident from high negative bias compared to the other two methods (Table 2). On comparing $R_{\mathrm{S}}$ and $R_{\mathrm{S}}$ TOA methods, the $R_{\mathrm{S}}$-based method performed relatively better than the $R_{\mathrm{S}}$ TOA scheme for low magnitude of $\tau$ (i.e. under predominantly cloudy sky). However, the results 
Table 2. A summary of $\mathrm{ET}_{\mathrm{d}}$ error statistics by comparing the performance of $R_{\mathrm{S}}$-based, $R_{\mathrm{S}} \mathrm{TOA}$-based and EF-based ET $i$ upscaling methods with regard to different sky conditions. Here $\tau_{1}$ represents low atmospheric transmissivity due to high cloudiness while $\tau_{4}$ represents high transmissivity under clear sky conditions.

\begin{tabular}{|c|c|c|c|c|c|c|c|c|c|c|c|c|c|c|c|c|}
\hline \multirow[b]{2}{*}{ Time of day (LT) } & \multirow[b]{2}{*}{$\tau$} & \multicolumn{3}{|c|}{$R^{2}$} & \multicolumn{3}{|c|}{$\operatorname{RMSE}\left(\mathrm{MJ} \mathrm{m}^{-2} \mathrm{~d}^{-1}\right)$} & \multicolumn{3}{|c|}{ IA } & \multicolumn{3}{|c|}{ MAPE (\%) } & \multicolumn{3}{|c|}{$\operatorname{Bias}\left(\mathrm{MJ} \mathrm{m}^{-2} \mathrm{~d}^{-1}\right)$} \\
\hline & & $R_{\mathrm{S}}$ & $R_{\mathrm{S}} \mathrm{TOA}$ & $\mathrm{EF}$ & $R_{\mathrm{S}}$ & $R_{\mathrm{S}} \mathrm{TOA}$ & $\mathrm{EF}$ & $R_{\mathrm{S}}$ & $R_{\mathrm{S}} \mathrm{TOA}$ & EF & $R_{\mathrm{S}}$ & $R_{\mathrm{S}} \mathrm{TOA}$ & $\mathrm{EF}$ & $R_{\mathrm{S}}$ & $R_{\mathrm{S}} \mathrm{TOA}$ & EF \\
\hline \multirow[t]{4}{*}{ 11:00 } & $\tau_{1}$ & 0.49 & 0.32 & 0.32 & 1.34 & 1.65 & 2.07 & 0.72 & 0.67 & 0.71 & 50.14 & 66.70 & 64.19 & -0.13 & -0.04 & 0.05 \\
\hline & $\tau_{2}$ & 0.72 & 0.70 & 0.69 & 1.73 & 1.81 & 1.93 & 0.81 & 0.78 & 0.69 & 26.47 & 32.41 & 36.42 & -0.21 & -0.19 & -0.95 \\
\hline & $\tau_{3}$ & 0.72 & 0.73 & 0.79 & 1.99 & 1.94 & 2.38 & 0.81 & 0.79 & 0.59 & 24.69 & 25.66 & 40.37 & -0.24 & -0.37 & -1.78 \\
\hline & $\tau_{4}$ & 0.77 & 0.81 & 0.68 & 1.32 & 1.13 & 2.00 & 0.84 & 0.81 & 0.49 & 32.17 & 30.02 & 55.43 & 0.05 & -0.19 & -1.34 \\
\hline \multirow[t]{4}{*}{$13: 30$} & $\tau_{1}$ & 0.52 & 0.34 & 0.29 & 1.21 & 1.68 & 2.34 & 0.73 & 0.69 & 0.71 & 48.29 & 66.09 & 68.14 & -0.11 & 0.08 & 0.12 \\
\hline & $\tau_{2}$ & 0.73 & 0.72 & 0.71 & 1.71 & 1.93 & 1.86 & 0.82 & 0.79 & 0.71 & 26.12 & 33.71 & 35.33 & -0.01 & 0.24 & -0.88 \\
\hline & $\tau_{3}$ & 0.75 & 0.75 & 0.76 & 1.89 & 1.96 & 2.43 & 0.82 & 0.82 & 0.61 & 23.17 & 25.82 & 41.65 & 0.09 & 0.14 & -1.75 \\
\hline & $\tau_{4}$ & 0.79 & 0.86 & 0.80 & 1.32 & 1.09 & 1.86 & 0.84 & 0.86 & 0.49 & 29.54 & 26.59 & 53.91 & 0.10 & 0.11 & -1.38 \\
\hline
\end{tabular}

(a)

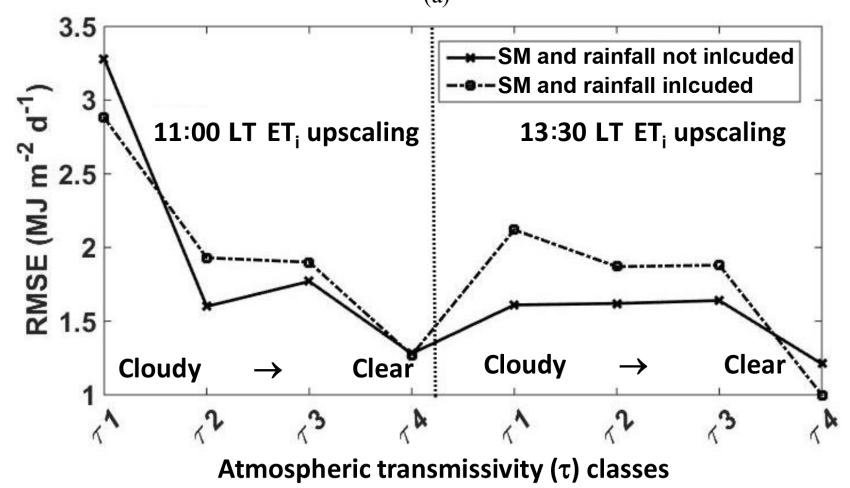

(b)

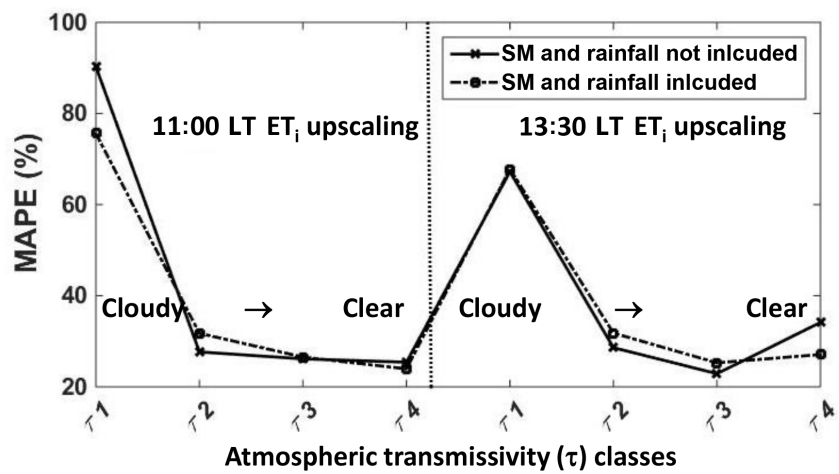

Figure 9. An intercomparison of $\mathrm{ET}_{\mathrm{d} \_ \text {pred }}$ error statistics (RMSE and MAPE) for different levels of atmospheric transmissivity classes based on two different ANN training (ANN trained with shortwave radiation and astronomical variables only; and ANN trained with radiation, astronomical variables, soil moisture, and rainfall) based on 11:00 and 13:30 LT time-of-day $\mathrm{ET}_{i}$ scaling.

suggest comparable performance of the $R_{\mathrm{S}} \mathrm{TOA}$-based approach under clear sky conditions which are reflected in the lowest RMSE (1.09 and $1.13 \mathrm{MJ} \mathrm{m}^{-2} \mathrm{~d}^{-1}$ ) in $\mathrm{ET}_{\mathrm{d} \_ \text {pred }}$ compared to the other $\tau$ classes. In general, all the schemes performed relatively better from the afternoon upscaling compared to the morning upscaling (as evidenced in higher $R^{2}$
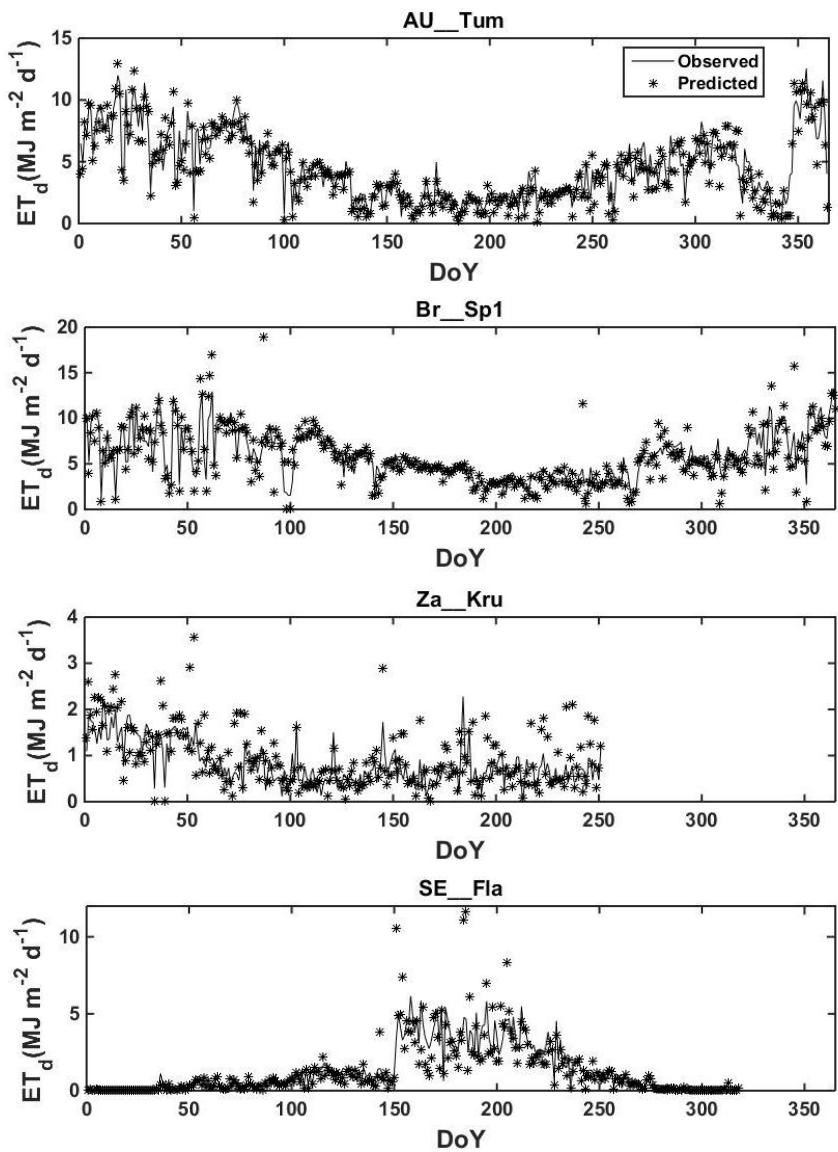

Figure 10. Time series comparison between observed and predicted $\mathrm{ET}_{\mathrm{d}}$ for four representative sites located in Australia, Brazil, South Africa, and Sweden.

and lower bias; Table 2) which is in agreement with the findings from Ryu et al. (2012). Due to their comparable error statistics, an intercomparison of $R_{\mathrm{S}}$ and $R_{\mathrm{S}} \mathrm{TOA}$-based methods of $\mathrm{ET}_{i}$ upscaling was also carried out across different biomes. 
(a) $R_{S}$-based RMSE of $E T_{d-p r e d}$

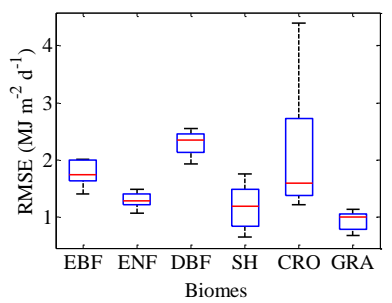

(c) $R_{S} T O A$-based RMSE of $E T_{d_{-} \text {pred }}$

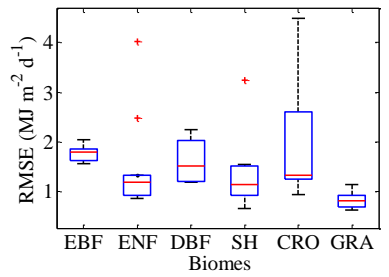

(b) $R_{S}$-based $\mathrm{R}^{2}$ of $E T_{\text {d_pred }}$

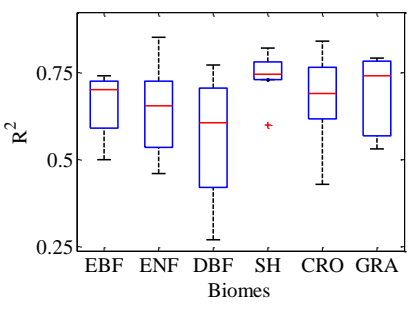

(d) $R_{S} T O A$-based $\mathrm{R}^{2}$ of $E T_{\text {dpred }}$

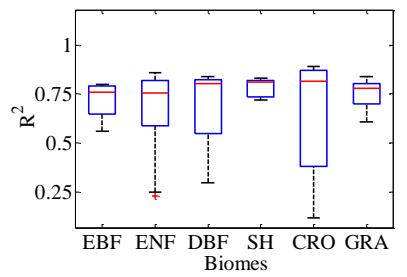

Figure 11. Biome-specific error characteristics of $E_{\text {d_pred }}$ displaying the box plots of RMSE and coefficient of determination $\left(R^{2}\right)$ from both $R_{\mathrm{S}}$-based and $R_{\mathrm{S}}$ TOA-based $\mathrm{ET}_{i}$ upscaling. The biome classes are evergreen broadleaf forest $(\mathrm{EBF})$, evergreen needleleaf forest (ENF), deciduous broadleaf forest (DBF), shrubland (SH), cropland (CRO), and grassland (GRA), respectively.

Biome-specific evaluation of $R_{\mathrm{S}}$-based $E T_{\mathrm{d} \_ \text {pred }}$ (Fig. 11) revealed the lowest RMSE and highest $R^{2}$ both in the grassland (GRA; 0.68 to $1.14 \mathrm{MJ} \mathrm{m}^{-2} \mathrm{~d}^{-1} ; 0.53$ to 0.79 ) and shrubland $\left(\mathrm{SH} ; 0.66\right.$ to $1.76 \mathrm{MJ} \mathrm{m}^{-2} \mathrm{~d}^{-1} ; 0.60$ to 0.82) whereas the RMSE was comparatively high over the tropical evergreen broadleaf forests (EBF; 1.41 to $2.02 \mathrm{MJ} \mathrm{m}^{-2} \mathrm{~d}^{-1}$ ) and deciduous broadleaf forests (DBF; 1.94 to $\left.2.55 \mathrm{MJ} \mathrm{m}^{-2} \mathrm{~d}^{-1}\right)$. Similar evaluation with the $R_{\mathrm{S}}$ TOA-based method revealed the lowest RMSE and highest $R^{2}$ in the grassland $\left(0.64\right.$ to $1.14 \mathrm{MJ} \mathrm{m}^{-2} \mathrm{~d}^{-1} ; 0.61$ to 0.84 ), and highest RMSE in EBF, DBF, and evergreen needleleaf forests (ENF; 1.57 to $2.05,1.2$ to 2.25 and 0.93 to $4.02 \mathrm{MJ} \mathrm{m}^{-2} \mathrm{~d}^{-1}$; Fig. $11 \mathrm{c}$ and d). Higher ET $_{\mathrm{d} \_ \text {pred }}$ errors in forests are related to the predominant cloudy-sky issue as described earlier. Tropical evergreen broadleaf forests (and forests in general) have high ET and water tends to re-cycle locally and generate rainfall. Therefore, cloudy sky conditions are more frequent in the tropical evergreen broadleaf forest and other forest types than in grassland and shrublands. In the biome-specific ET $_{\mathrm{d} \_ \text {pred }}$ error statistics (Fig. 11), a relatively large bias in crop ET $_{\mathrm{d}_{\text {_pred }}}$ is introduced due to the inclusion of irrigated agroecosystems in the validation. In irrigated agroecosystems, day-to-day variation in soil moisture is not substantial and $\mathrm{ET}_{\mathrm{d}}$ is predominantly controlled by the net radiation. Therefore, the inclusion of soil moisture in the current ANN framework is unlikely to improve $E_{d_{-} \text {pred }}$ statistics in the irrigated agroecosystems. Further, having many explanatory variables (e.g. land management, irrigation statistics, anthropogenic factors) to train the ANN,

we risk overfitting the model and hence introducing bias. It is also evident that both $R_{S}$ and $R_{S}$ TOA-based method of $\mathrm{ET}_{\mathrm{d}}$ estimation would be better suited for natural ecosystems, e.g. in the Amazon basin or in the forest ecosystems where significant hydrological and climatological projections are emphasising the role of $\mathrm{ET}_{\mathrm{d}}$ to understand the resilience of natural ecosystems in the spectre of hydro-climatological extremes (Harper et al., 2014; Kim et al., 2012). The performance of the method in the semi-arid shrublands appear to be promising (Fig. 11), and therefore the method also seems to be credible under water-stressed environments.

Given that this analysis was based on FLUXNET sites distributed across $0-90^{\circ}$ latitude north and south, the training datasets cover substantial climatic and vegetation variability. The percentage distribution of the training data according to vegetation type was $23 \%$ crops, $31 \%$ deciduous broadleaf forest, $10 \%$ evergreen broadleaf forest, $20 \%$ evergreen need leaf forest, $8 \%$ grassland, $7 \%$ shrubs and $1 \%$ aquatic, as indicated in Table S1. The number of grassland and shrubs as indicated were relatively fewer compared to the crops and forest sites. However, biome-specific error statistics (Fig. 11) indicated the absence of any systematic errors due to vegetation sampling with the exception of EBF. Availability of more EBF sites in the training datasets is expected to reduce the cloudy-sky errors substantially, due to the assimilation of more cloud information into the $R_{\mathrm{S}}$-based ANN training.

The tendency towards positive bias in $\mathrm{ET}_{\mathrm{d} \_ \text {pred }}$ from both $R_{\mathrm{S}}$ and $R_{\mathrm{S}}$ TOA in clear skies from afternoon upscaling is partly explained by the fact that, during the afternoon, the values of both $R_{\mathrm{S}}$ and $R_{\mathrm{S}}$ TOA reached maximum limit and this dominates their daily values (Jackson et al., 1983). The post-afternoon rate of reduction in ET does not coincide with the shortwave radiation due to stomatal controls on ET, and the total water flux from morning to afternoon (07:00 to 13:00 LT) is generally greater than the total water flux from post afternoon (15:00 LT onwards) till sunset. Therefore multiplying 13:30 LT $\mathrm{ET}_{i}$ with high magnitudes of $R_{\mathrm{Sd}} / R_{\mathrm{Si}}$ or $R_{\mathrm{Sd}}$ TOA $/ R_{\mathrm{Si}}$ TOA might lead to an overestimation of $\mathrm{ET}_{\mathrm{d} \_ \text {pred }}$ in the clear-sky days.

Since extraterrestrial shortwave radiation is not affected by the clouds, $\mathrm{ET}_{\mathrm{d} \_ \text {pred }}$ from $R_{\mathrm{S}} \mathrm{TOA}$ performed comparably with the $R_{\mathrm{S}}$-based $\mathrm{ET}_{\mathrm{d} \_ \text {pred }}$ with increasing atmospheric clearness (i.e. for the higher levels of daily $\tau$ ). However, increased differences in the RMSE of $\mathrm{ET}_{\mathrm{d} \_ \text {pred }}$ between $R_{\mathrm{S}}$ and $R_{\mathrm{S}}$ TOA upscaling in the predominantly cloudy days indicates that more deviations can be expected in $\mathrm{ET}_{\mathrm{d}_{-} \text {pred }}$ from these two different methods of upscaling under principally overcast conditions (Tang et al., 2013). This happens because the ratio of $R_{\mathrm{Sd}} \mathrm{TOA} / R_{\mathrm{Si}}$ TOA is not impacted by the clouds and the magnitude of this ratio becomes markedly different from the $R_{\mathrm{Sd}} / R_{\mathrm{Si}}$ ratio in the presence of clouds, which leads to the differences in ET $_{\text {d_pred }}$ between them. The $R_{\mathrm{S}}$-based method is relatively efficient for discriminating between the impacts on ET by $R_{\mathrm{Sd}} / R_{\mathrm{Si}}$ due to the clouds. The generally good performance of the $R_{\mathrm{S}}$-based 
(a) 11:00 LT ET $T_{i}$ upscaling
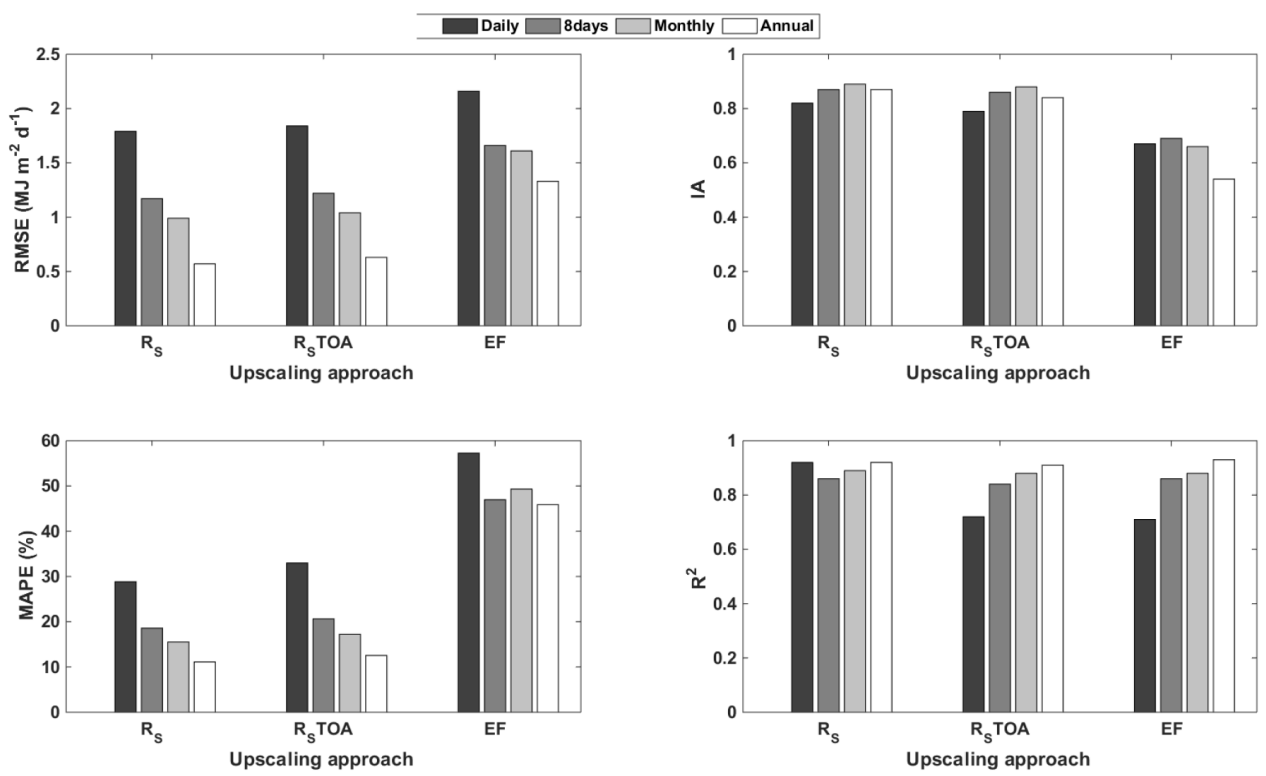

(b) 13:30 LT $E T_{i}$ upscaling
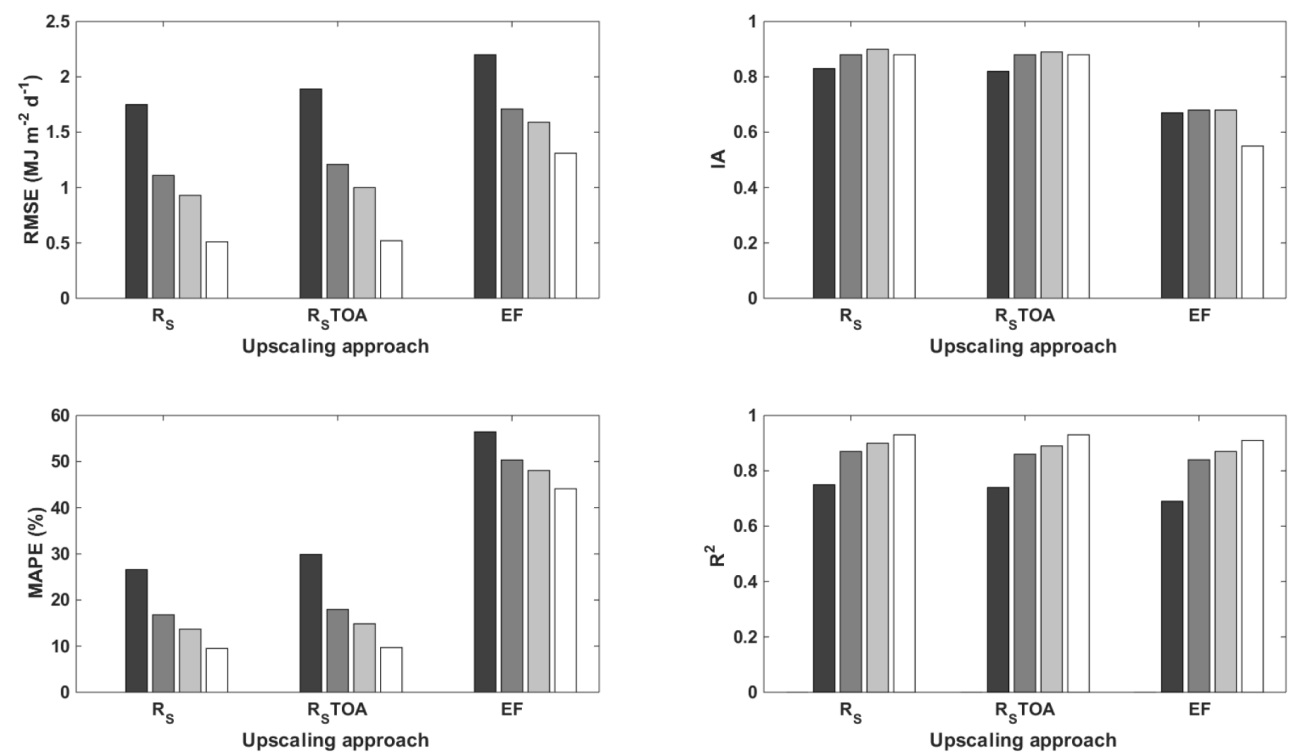

Figure 12. Statistical metrics of $\mathrm{ET}_{\mathrm{d} \_ \text {pred }}$ from three different $\mathrm{ET}_{i}$ upscaling approaches [shortwave incoming radiation $\left(R_{\mathrm{S}}\right)$, exoatmospheric shortwave radiation $\left(R_{\mathrm{S}} \mathrm{TOA}\right)$ and evaporative fraction $(\mathrm{EF})$ ] at different temporal scales based on $\mathrm{ET}_{i}$ measurements at (a) 11:00 LT and (b) 13:30 LT times of day.

method and comparable error statistics with $R_{\mathrm{S}}$ TOA-based $\mathrm{ET}_{\mathrm{d}}$ estimates are consistent with the findings of Cammalleri et al. (2014) and Van Niel et al. (2012). As shown in Table 2, relatively lower RMSE of $R_{\mathrm{S}} \mathrm{TOA}$-based $\mathrm{ET}_{\mathrm{d} \_ \text {pred }}$ for atmospheric transmissivity class above 0.75 reveals that under pristine clear sky conditions $R_{\mathrm{S}} \mathrm{TOA}$ can be successfully used to upscale $\mathrm{ET}_{i}$. However, one of the main reasons for the differences in RMSE between $R_{\mathrm{S}}$ and the $R_{\mathrm{S}} \mathrm{TOA}$ method for daily transmissivity above 0.75 could be due to the fact that if $\mathrm{ET}_{i}$ upscaling is performed from a cloudy in- stance for a predominantly clear sky day, then such RMSE difference between the two different upscaling methods is expected. These results also revealed the probability of a hybrid $\mathrm{ET}_{i}$ upscaling method by combining cloud information or SM and $P$ in $R_{\mathrm{S}}$-method (for transmissivity between zero and 0.5 ) and $R_{\mathrm{S}}$ TOA-method (for transmissivity greater than 0.5 ). However this hypothesis needs to be tested further.

The systematic $\mathrm{ET}_{\mathrm{d}}$ underestimation by the EF-based upscaling method and nearly similar pattern of bias from two different time-of-day upscaling (Table 2) further point to the 
Table 3. Error statistics of $\mathrm{ET}_{\mathrm{d} \_ \text {pred }}$ at four different temporal scales from three $\mathrm{ET}_{i}$ upscaling methods.

\begin{tabular}{|c|c|c|c|c|c|c|c|c|c|c|c|c|c|c|c|c|}
\hline \multirow[b]{2}{*}{$\begin{array}{l}\text { Time of day } \\
\text { (LT) }\end{array}$} & \multirow[b]{2}{*}{$\begin{array}{r}\text { Temporal } \\
\text { scale }\end{array}$} & \multicolumn{3}{|c|}{$R^{2}$} & \multicolumn{3}{|c|}{$\operatorname{RMSE}\left(\mathrm{MJ} \mathrm{m}^{-2} \mathrm{~d}^{-1}\right)$} & \multicolumn{3}{|c|}{ IA } & \multicolumn{3}{|c|}{ MAPE (\%) } & \multicolumn{3}{|c|}{$\operatorname{Bias}\left(\mathrm{MJ} \mathrm{m}^{-2} \mathrm{~d}^{-1}\right)$} \\
\hline & & $R_{\mathrm{S}}$ & $R_{\mathrm{S}} \mathrm{TOA}$ & $\mathrm{EF}$ & $R_{\mathrm{S}}$ & $R_{\mathrm{S}} \mathrm{TOA}$ & $\mathrm{EF}$ & $R_{\mathrm{S}}$ & $R_{\mathrm{S}} \mathrm{TOA}$ & $\mathrm{EF}$ & $R_{\mathrm{S}}$ & $R_{\mathrm{S}} \mathrm{TOA}$ & $\mathrm{EF}$ & $R_{\mathrm{S}}$ & $R_{\mathrm{S}} \mathrm{TOA}$ & $\mathrm{EF}$ \\
\hline \multirow[t]{4}{*}{$11: 00$} & Daily & 0.71 & 0.72 & 0.71 & 1.79 & 1.85 & 2.16 & 0.82 & 0.80 & 0.67 & 28.80 & 32.98 & 57.00 & 0.19 & 0.22 & 1.21 \\
\hline & 8-day & 0.86 & 0.84 & 0.85 & 1.17 & 1.22 & 1.65 & 0.87 & 0.86 & 0.67 & 18.50 & 20.63 & 46.96 & 0.19 & 0.22 & 1.16 \\
\hline & Monthly & 0.89 & 0.88 & 0.88 & 0.99 & 1.04 & 1.61 & 0.89 & 0.67 & 0.67 & 15.52 & 17.22 & 49.72 & 0.19 & 0.22 & 1.16 \\
\hline & Annually & 0.92 & 0.91 & 0.93 & 0.57 & 0.62 & 1.33 & 0.87 & 0.84 & 0.54 & 11.12 & 12.54 & 45.88 & 0.19 & 0.22 & 1.21 \\
\hline \multirow[t]{4}{*}{$13: 30$} & Daily & 0.75 & 0.74 & 0.69 & 1.74 & 1.89 & 2.20 & 0.83 & 0.82 & 0.67 & 26.59 & 29.89 & 56.45 & -0.04 & 0.17 & -1.18 \\
\hline & 8-day & 0.87 & 0.86 & 0.84 & 1.11 & 1.21 & 1.70 & 0.88 & 0.88 & 0.68 & 16.80 & 17.97 & 50.36 & -0.04 & 0.17 & -1.18 \\
\hline & Monthly & 0.90 & 0.90 & 0.87 & 0.93 & 1.00 & 1.59 & 0.90 & 0.89 & 0.68 & 13.69 & 14.85 & 48.08 & -0.04 & 0.17 & -1.18 \\
\hline & Annually & 0.93 & 0.93 & 0.92 & 0.51 & 0.53 & 1.31 & 0.88 & 0.88 & 0.54 & 9.00 & 9.70 & 44.13 & -0.04 & 0.17 & -1.18 \\
\hline
\end{tabular}

(a) $\mathrm{R}^{2}$ of $E T_{\text {d_pred }}$ for three different ANN training scenarios

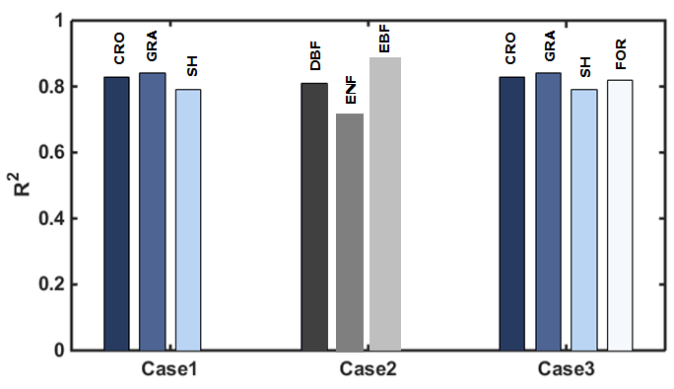

(b) RMSE of $E T_{d \text { pred }}$ for three different ANN training scenarios

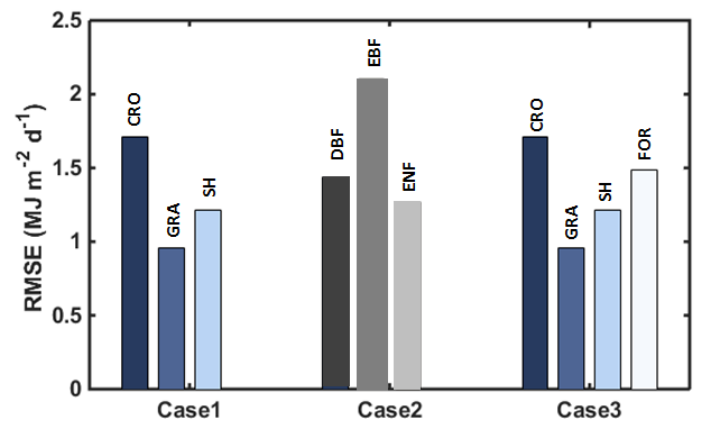

Figure 13. Illustrative examples of the sensitivity of $\mathrm{ET}_{\mathrm{d} \_ \text {pred }}$ error statistics ( $R^{2}$ and RMSE) to the different biome type scenarios of ANN training. Here, Case 1 consist of training the ANN with forest (FOR) datasets and evaluating ANN predicted $\mathrm{ET}_{\mathrm{d}}$ statistics on non-forest biomes, Case 2 consist of training the ANN with nonforest datasets and evaluating ANN predicted $\mathrm{ET}_{\mathrm{d}}$ statistics on forest biomes, Case 3 consist of training the ANN with both forests and non-forest datasets and evaluating $\mathrm{ANN}$ predicted $\mathrm{ET}_{\mathrm{d}}$ statistics on all the biomes.

fact that the concave-up shape of EF during daytime (Hoedjes et al., 2008; Tang et al., 2013) will tend to underestimate $\mathrm{ET}_{\mathrm{d}}$ if $\mathrm{EF}$ is assumed to be conservative during the daytime. EF remains conservative during the daytime under extremely dry conditions when $\mathrm{ET}_{\mathrm{d}}$ is solely driven by deep-layer soil moisture. The systematic underestimation of $\mathrm{ET}_{\mathrm{d}}$ from the EF-based upscaling method corroborates with the results reported by other researchers (Cammalleri et al., 2014; Del- ogu et al., 2012; Gentine et al., 2007; Hoedjes et al., 2008), which suggests that the self-preservation of EF is not generally achieved, and this systematic underestimation of $\mathrm{ET}_{\mathrm{d}}$ can be partially compensated if EF-based ET $_{i}$ upscaling is done from morning (09:00 LT) or afternoon (16:00 LT) times of day.

We further resampled $\mathrm{ET}_{\mathrm{d}}$ (both predicted and observed) from daily to 8-day, monthly, and annual scale, and statistical metrics from the three different upscaling methods at three different temporal scales are shown in Fig. 12 and Table 3. Averaging $\mathrm{ET}_{\mathrm{d}}$ at 8-day, monthly and annual scale substantially reduced the RMSE to the order of 60 to $70 \%$ for all three upscaling methods. The $R_{\mathrm{S}}$-based upscaled $\mathrm{ET}_{\mathrm{d}}$ from morning and afternoon showed reduction in RMSE from 1.79 to 0.57 and 1.74 to $0.51 \mathrm{MJ}$ from daily to annual ET, respectively. For the other two upscaling methods these statistics varied from 1.85 and 1.89 to 0.62 and $0.53 \mathrm{MJ}\left(R_{\mathrm{S}} \mathrm{TOA}\right.$ method), and 2.16 and 1.33 to 2.20 and $1.31 \mathrm{MJ}$ (EF method; Fig. 12 and Table 3). The impacts of daily cloud variability might have smoothed out in 8-day, monthly and annual scale which led to reduced RMSE and higher correlation between $\mathrm{ET}_{\mathrm{d}_{-} \text {pred }}$ and $\mathrm{ET}_{\mathrm{d} \_ \text {obs. }}$. Nearly similar error statistics in $\mathrm{ET}_{\mathrm{d} \_ \text {pred }}$ from both the morning and afternoon upscaling also substantiates the findings of Ryu et al. (2012) and greatly stimulate the use of either morning satellite (i.e. Terra) or afternoon satellite (i.e. Aqua) to upscale $\mathrm{ET}_{i}$ to $\mathrm{ET}_{\mathrm{d}}$ or 8-day mean $\mathrm{ET}_{\mathrm{d}}$.

The principal limitation of the approach is the dependence of $\mathrm{ET}_{\mathrm{d}}$ and $R_{\mathrm{Sd}}$ on a single snapshot of $\mathrm{ET}_{i}$ and $R_{\mathrm{Si}}$, although hourly $R_{\mathrm{S}}$ data from geostationary satellites are becoming available. However these are available as sectorial products (i.e. for particular continents) instead of full global coverage. Ongoing efforts to develop geostationary-based data by merging multiple geostationary satellites tend to overcome this limitation.

\subsection{Impact of energy balance closure on $\mathbf{E T}_{\mathbf{d} \_ \text {pred }}$}

FLUXNET EC sites have long been identified as prone to surface energy budget imbalance, which might lead to $\pm 20 \%$ to $\pm 40 \%$ under measurement of latent heat fluxes. In order 
Table 4. Evaluation of the $R_{\mathrm{S}}$-based ANN-predicted $\mathrm{ET}_{\mathrm{d}}\left(\mathrm{ET}_{\mathrm{d} \_ \text {pred }}\right)$ error statistics based on "closed" (EBC) and "unclosed" (EBO) surface energy balance under varying sky conditions represented by four different classes of daily atmospheric transmissivity $(\tau)$. Here $\tau_{1}$ represents low atmospheric transmissivity due to high cloudiness while $\tau_{4}$ represents high transmissivity under clear sky conditions. The statistical metrics of $\mathrm{ET}_{\mathrm{d} \_ \text {pred }}$ for two different upscaling hours (11:00 and 13:30 LT) are presented.

\begin{tabular}{|c|c|c|c|c|c|c|c|c|c|c|c|}
\hline \multirow[b]{2}{*}{ Time of day (LT) } & \multirow[b]{2}{*}{$\tau$} & \multicolumn{2}{|c|}{$R^{2}$} & \multicolumn{2}{|c|}{$\operatorname{RMSE}\left(\mathrm{MJ} \mathrm{m}^{-2} \mathrm{~d}^{-1}\right)$} & \multicolumn{2}{|c|}{ IA } & \multicolumn{2}{|c|}{ MAPE (\%) } & \multicolumn{2}{|c|}{$\operatorname{Bias}\left(\mathrm{MJ} \mathrm{m}^{-2} \mathrm{~d}^{-1}\right)$} \\
\hline & & EBO & EBC & $\mathrm{EBO}$ & $\mathrm{EBC}$ & EBO & EBC & EBO & $\mathrm{EBC}$ & EBO & $\mathrm{EBC}$ \\
\hline \multirow[t]{4}{*}{ 11:00 } & $\tau_{1}$ & 0.37 & 0.17 & 2.96 & 3.31 & 0.71 & 0.57 & 87.21 & 86.49 & 0.66 & 1.12 \\
\hline & $\tau_{2}$ & 0.68 & 0.54 & 1.64 & 2.94 & 0.78 & 0.68 & 28.66 & 38.01 & -0.10 & 0.65 \\
\hline & $\tau_{3}$ & 0.75 & 0.61 & 1.77 & 3.20 & 0.76 & 0.66 & 25.31 & 37.82 & -0.67 & 1.34 \\
\hline & $\tau_{4}$ & 0.66 & 0.61 & 1.09 & 3.40 & 0.71 & 0.30 & 21.77 & 85.80 & -0.31 & 3.83 \\
\hline \multirow[t]{4}{*}{$13: 30$} & $\tau_{1}$ & 0.35 & 0.25 & 2.02 & 2.70 & 0.71 & 0.60 & 69.78 & 78.18 & 0.37 & 0.87 \\
\hline & $\tau_{2}$ & 0.76 & 0.50 & 1.54 & 3.27 & 0.81 & 0.69 & 27.56 & 40.98 & 0.23 & 0.63 \\
\hline & $\tau_{3}$ & 0.77 & 0.59 & 1.66 & 3.18 & 0.80 & 0.70 & 23.16 & 34.17 & -0.46 & 0.76 \\
\hline & $\tau_{4}$ & 0.84 & 0.64 & 0.98 & 2.46 & 0.76 & 0.66 & 23.30 & 43.89 & -0.56 & 1.23 \\
\hline
\end{tabular}

to assess the impacts of surface energy balance (SEB) closure on current $\mathrm{ET}_{\mathrm{d}}$ prediction, we further compared the error statistics of $R_{\mathrm{S}}$-based $\mathrm{ET}_{\mathrm{d} \_ \text {pred }}$ (Table 4 ) for both "closed" and "unclosed" surface energy balance datasets. These are the subsets of the data where all four SEB components $(\lambda E$, sensible heat flux, ground heat flux, and net radiation) were available and SEB was closed by the residual SEB closure method (Foken, 2006). Table 4 revealed substantially low RMSE (10 to $60 \%$ ), $R^{2}$ (8 to $100 \%$ ) and MAPE (1 to $75 \%$ ) in $\mathrm{ET}_{\text {d_pred }}$ when $\mathrm{ET}_{i}$ upscaling is done by "unclosed" SEB. A consistently high positive mean bias (0.63 to 3.83) in $E_{\text {d_pred }}$ with "closed" SEB was also noted (Table 4). Although various methods exist to close the surface energy balance, the impact of various SEB closure methods on $\mathrm{ET}_{\mathrm{d}_{-} \text {pred }}$ statistics is beyond the scope of the current study. It is also important to mention that in the satellite-based $\mathrm{ET}_{i}$ retrieval, net available energy is partitioned into ET and sensible heat flux with the implicit assumption of SEB closure. Therefore, application of the current ANN framework is expected not to impact the remote-sensing-based $\mathrm{ET}_{i}$ to $\mathrm{ET}_{\mathrm{d}}$ upscaling. However, for the validation of remote-sensing-based $\mathrm{ET}_{\mathrm{d}}$ retrievals, surface energy balance fluxes from eddy covariance measurements need to be closed.

\subsection{Sensitivity of ANN-derived ET $_{d_{-} \text {pred }}$ to biome selection}

A sensitivity analysis of $\mathrm{ANN}$-derived $R_{\mathrm{S}}$-based $\mathrm{ET}_{\mathrm{d} \_ \text {pred }}$ revealed variable sensitivity of the ANN framework to the biome selection. The coefficient of determination $\left(R^{2}\right)$ varied between 0.71 and 0.84 and RMSE between 0.96 and $2.10 \mathrm{MJ} \mathrm{m}^{-2} \mathrm{~d}^{-1}$ across three different scenarios of ANN training and validation (Fig. 13). However, RMSE was found to be relatively high in forests in Case2, where ANN was trained by using the data from crops, grasslands, and shrublands only. For Case1 and Case3, no substantial difference was noted (Fig. 13). This therefore revealed the fact that the inclusion of forests in ANN training leads to lower errors in $\mathrm{ET}_{\mathrm{d} \_ \text {pred }}$ over non-forest biomes, although the reverse scenario in not likely to be true. Since forests generally have high ET, water recycling tends to be more over the forests, which produces substantial rainfall, variable atmospheric water vapour, associated cloudiness, and radiation. Cloudiness is a phenomenon that significantly influences the reliability of a model to predict incoming solar radiation as they are directly related to each other. Therefore, when $R_{\mathrm{S}}$-based ANN is trained with data from forests, the model assimilates information on a diverse range of radiative forcings which broaden their applicability in other biomes. This also emphasises the fact that the performance of such an ANN-based approach is primarily sensitive to their training over a broad spectrum of atmospheric conditions.

\section{Summary and conclusions}

Given the significance of $\mathrm{ET}_{\mathrm{d}}$ in remote-sensing-based water resource management from polar orbiting satellites, this study developed and evaluated a temporal upscaling method for estimating $\mathrm{ET}_{\mathrm{d}}$ from different time-of-day instantaneous ET $\left(\mathrm{ET}_{i}\right)$ measurements with the assumption that the ratio between daytime and instantaneous shortwave radiation $\left(R_{\mathrm{Sd}} / R_{\mathrm{Si}}\right)$ is the predominant factor governing the $\mathrm{ET}_{\mathrm{d}} / \mathrm{ET}_{i}$ ratio. However, since $R_{\mathrm{Sd}}$ is not directly measurable from the polar orbiting satellites, we trained an ANN with the FLUXNET observations of $R_{\mathrm{Si}}$ and $R_{\mathrm{Sd}}$, and validated the model to predict $R_{\mathrm{Sd}}$ over independent sites, followed by using the $R_{\mathrm{Sd}} / R_{\mathrm{Si}}$ ratio for converting $\mathrm{ET}_{i}$ to $\mathrm{ET}_{\mathrm{d}}$. The overarching goal of this study is to provide an operational and robust $\mathrm{ET}_{i}$ upscaling protocol for estimating $\mathrm{ET}_{\mathrm{d}}$ from any polar orbiting satellite. The datasets used for the ANN model development covers a wide range of biome, climate, and variable sky conditions. Therefore, we assume that the $R_{\mathrm{Sd}}$ prediction from ANN captures a broad spectrum of 
radiative forcings, which is also reflected in the independent validation of $R_{\mathrm{Sd}}$ and $\mathrm{ET}_{\mathrm{d}}$ (Figs. 5, 7, Table 2). However, the performance of this model for satellite retrieval of $R_{\mathrm{Sd}}$ (from $R_{\mathrm{Si}}$ ) is dependent on the accuracy of $R_{\mathrm{Si}}$ retrieval (Loew et al., 2016). Also, the distribution of sites over the tropics, Africa, and South-East Asia is poor, and availability of more sites in these regions is expected to make the ANN model performance more robust.

Based on measurements from 126 flux tower sites, we found $R_{\mathrm{S}}$-based upscaled $\mathrm{ET}_{\mathrm{d}}$ to produce a significant linear relation $\left(R^{2}=0.65\right.$ to 0.69$)$, little bias $(-0.31$ to $-0.56 \mathrm{MJ} \mathrm{m}^{-2} \mathrm{~d}^{-1}$; approx. $4 \%$ ), and good agreement (RMSE 1.55 to $1.86 \mathrm{MJ} \mathrm{m}^{-2} \mathrm{~d}^{-1}$; approx. $10 \%$ ) with the observed $\mathrm{ET}_{\mathrm{d}}$. While the exoatmospheric shortwave-radiationdriven $\mathrm{ET}_{i}$ upscaling method (i.e. $R_{\mathrm{S}} \mathrm{TOA}$-based) appeared to produce slightly lower RMSE (10\% lower) under cloudfree conditions (Table 2), the global shortwave-radiationdriven method (i.e. $R_{\mathrm{S}}$-based method) demonstrates more robust performance and was found to be better under cloudy conditions. Despite the $R_{\mathrm{S}}$-based method yielding relatively better overall accuracy in $\mathrm{ET}_{\mathrm{d}}$ prediction (i.e. $\mathrm{ET}_{\mathrm{d} \_ \text {pred }}$ ) statistics when compared with the $R_{\mathrm{S}} \mathrm{TOA}$ and evaporativefraction-based (EF-based) method, statistical analysis of $\mathrm{ET}_{\text {d_pred }}$ accuracy of different temporal upscaling methods (as discussed in Sect. 3.3) suggests that both $R_{\mathrm{S}}$ and $R_{\mathrm{S}} \mathrm{TOA}$ methods produce commensurate results under coarse temporal resolutions (Table 3). Therefore, at the coarse temporal scale (8-day and above), any of these two methods ( $R_{\mathrm{S}}$ and $R_{\mathrm{S}} \mathrm{TOA}$ ) can be used for $\mathrm{ET}_{i}$ to $\mathrm{ET}_{\mathrm{d}}$ upscaling.

The proposed upscaling method is based on the idea that instantaneous ET / $R_{\mathrm{S}}$ approximates daily ET / $R_{\mathrm{S}}$, although it implicitly includes the stomatal controls on ET observations mediated by the vegetation. The cases where $\mathrm{ET}_{i}$ is low due to water-stress-induced strong stomatal control; low magnitude of ET will also be reflected in upscaling $\mathrm{ET}_{i}$ to $\mathrm{ET}_{\mathrm{d}}$ (according to Eq. 1). However, to account for any carry-over effects of the stomatal control on $\mathrm{ET}_{\mathrm{d}}$, inclusion of longwave radiation information would likely improve the scheme. Stomatal control is significantly dependent on the thermal longwave radiative components, and, therefore, the relative proportion of downwelling and upwelling longwave radiation is expected to be a stomatal constraint. However, the availability of longwave radiation measurement stations in the FLUXNET datasets is limited to formulate ANN and evaluate this hypothesis. In general, the stomatal and biophysical constraints are imposed in state-of-the-art thermal remote-sensing-based $\mathrm{ET}_{i}$ retrieval schemes, and, therefore the ANN framework can be applied to upscale remotesensing-based $\mathrm{ET}_{i}$ to $\mathrm{ET}_{\mathrm{d}}$. Also, relatively good performance of the model in semi-arid shrubland further indicated the applicability of the method in water-stressed ecosystems where stomatal controls are predominant.

Among all the upscaling methods tested, the $R_{\mathrm{S}}$-based method carries maximum information on the cloudiness and generally produced the lowest RMSE, low bias (Table 3), and, therefore, overall the preferably robust scaling mechanism (at the daily scale). The true added value of the ANN is for an operational $\mathrm{ET}_{\mathrm{d}}$ product from polar satellites. Currently, the polar Earth orbiting satellites provide us with $\mathrm{ET}_{i}$ only. However, for most hydrological and ecosystem modelling applications, $\mathrm{ET}_{\mathrm{d}}$ is needed. Therefore, for studies that will opt to apply the $R_{\mathrm{S}}$-based method as a scaling algorithm, $R_{\mathrm{Sd}}$ can be retrievable from any measurement of $R_{\mathrm{Si}}$ by the satellite using the ANN. However, upscaling largearea satellite-based $\mathrm{ET}_{i}$ by using retrieved $R_{\mathrm{Si}}$ would require accurate $R_{\mathrm{Si}}$ retrieval techniques, which are currently commonplace (Ahmad et al., 2015; Boulifa et al., 2015; Dahmani et al., 2016; Hasni et al., 2012; Li et al., 2013), to support regional-scale hydrological applications. Of the two other upscaling methods, $R_{\mathrm{S}}$ TOA could be easily applied over large areas, had lower errors than EF, had the secondbest RMSE, and the overall lowest bias among the two. We conclude that using modelled $R_{\mathrm{S}}$ to upscale $\mathrm{ET}_{i}$ at daily scale appears to be viable for large-area hydrological remote sensing applications from polar orbiting satellites irrespective of any sky conditions.

\section{Data availability}

The FLUXNET eddy covariance datasets are available through http://fluxnet.fluxdata.org (Baldocchi et al., 2001).

\section{The Supplement related to this article is available online at doi:10.5194/hess-21-197-2017-supplement.}

Author contributions. Kaniska Mallick designed the analysis, Loise Wandera performed the research, Kaniska Mallick and Loise Wandera developed the manuscript, and all the coauthors jointly contributed to editing the manuscript.

Competing interests. The authors declare that they have no conflict of interest.

Acknowledgements. The authors thank the HiWET (High resolution modelling and monitoring of water and energy transfers in WETland ecosystems) project funded through the Belgian Science Policy (BELSPO) and FNR under the programme STEREOIII (INTER/STEREOIII/13/03/HiWET; CONTRACT NR SR/00/301). We thank the entire FLUXNET site PIs for sharing the eddy covariance data. This work used eddy covariance data acquired by the FLUXNET community and in particular by the following networks: AmeriFlux (US Department of Energy, Biological and Environmental Research, Terrestrial Carbon Program (DE-FG0204ER63917 and DE-FG02-04ER63911)), AfriFlux, AsiaFlux, 
CarboAfrica, CarboEuropeIP, CarboItaly, CarboMont, ChinaFlux, Fluxnet-Canada (supported by CFCAS, NSERC, BIOCAP, Environment Canada, and NRCan), GreenGrass, KoFlux, LBA, NECC, OzFlux, TCOS-Siberia, USCCC. We acknowledge the financial support to the eddy covariance data harmonisation provided by CarboEuropeIP, FAO-GTOS-TCO, iLEAPS, the Max Planck Institute for Biogeochemistry, the National Science Foundation, the University of Tuscia, Université Laval, Environment Canada and the US Department of Energy as well as the database development and technical support from the Berkeley Water Center, Lawrence Berkeley National Laboratory, Microsoft Research eScience, Oak Ridge National Laboratory, University of California, Berkeley, and the University of Virginia. Loise Wandera also acknowledges the $\mathrm{PhD}$ supervision from Wout Verhoef and Christian van der Tol from the University of Twente, the Netherlands.

Edited by: M. Coenders-Gerrits

Reviewed by: three anonymous referees

\section{References}

Ahmad, A., Anderson, T. N., and Lie, T. T.: Hourly global solar irradiation forecasting for New Zealand, Sol. Energy, 122, 13981408, doi:10.1016/j.solener.2015.10.055, 2015.

Allen, R. G., Pereira, L. S., Raes, D., and Smith, M.: Crop evapotranspiration, Guidelines for computing crop water requirements, FAO Irrigation and drainage paper, Rome, Italy, 56, 326 pp., 1998.

Anderson, R. G., Lo, M.-H., Swenson, S., Famiglietti, J. S., Tang, Q., Skaggs, T. H., Lin, Y.-H., and Wu, R.-J.: Using satellitebased estimates of evapotranspiration and groundwater changes to determine anthropogenic water fluxes in land surface models, Geosci. Model Dev., 8, 3021-3031, doi:10.5194/gmd-8-30212015, 2015.

Baigorria, G. A., Villegas, E. B., Trebejo, I., Carlos, J. F., and Quiroz, R.: Atmospheric transmissivity: distribution and empirical estimation around the central Andes, Int. J. Climatol., 24, 1121-1136, doi:10.1002/joc.1060, 2004.

Baldocchi, D. D., Falge, E., Gu, L. H., Olson, R., Hollinger, D., Running, S., Anthoni, P., Bernhofer, C., Davis, K., Evans, R., Fuentes, J., Goldstein, A., Katul, G., Law, B., Lee, X. H., Malhi, Y., Meyers, T., Munger, W., Oechel, W., Paw U, K. T., Pilegaard, K., Schmid, H. P., Valentini, R., Verma, S., Vesala, T., Wilson, K., and Wofsy, S.: Fluxnet: a new tool to study the temporal and spatial variability of ecosystem-scale carbon dioxide, water vapor, and energy flux densities, B. Am. Meteorol. Soc., 82, 24153434, 2001.

Bisht, G., Venturini, V., Islam, S., and Jiang, L.: Estimation of the net radiation using MODIS (Moderate Resolution Imaging Spectroradiometer) data for clear sky days, Remote Sens. Environ., 97, 52-67, doi:10.1016/j.rse.2005.03.014, 2005.

Boulifa, M., Adane, A., Rezagui, A., and Ameur, Z.: Estimate of the Global Solar Radiation by Cloudy Sky Using HRV Images, Energ. Proc., 74, 1079-1089, doi:10.1016/j.egypro.2015.07.747, 2015.

Brutsaert, W. and Sugita, M.: Application of self-preservation in the diurnal evolution of the surface energy budget to determine daily evaporation, J. Geophys. Res.-Atmos., 97, 18377-18382, doi:10.1029/92JD00255, 1992.

Burden, F. and Winkler, D.: Bayesian Regularization of Neural Networks, in: Artificial Neural Networks SE, edited by: Livingstone, D., Humana Press, 3, 458, 23-42, doi:10.1007/978-160327-101-1_3, 2009.

Cammalleri, C., Anderson, M. C., and Kustas, W. P.: Upscaling of evapotranspiration fluxes from instantaneous to daytime scales for thermal remote sensing applications, Hydrol. Earth Syst. Sci., 18, 1885-1894, doi:10.5194/hess-18-1885-2014, 2014.

Chávez, J. L., Neale, C. M. U., Prueger, J. H., and Kustas, W. P.: Daily evapotranspiration estimates from extrapolating instantaneous airborne remote sensing ET values, Irrigation Sci., 27, 6781, doi:10.1007/s00271-008-0122-3, 2008.

Chen, Z., Shi, R., and Zhang, S.: An artificial neural network approach to estimate evapotranspiration from remote sensing and AmeriFlux data, Front. Earth Sci., 7, 103-111, doi:10.1007/s11707-012-0346-7, 2013.

Colaizzi, P. D., Evett, S. R., Howell, T. A., and Tolk, J. A.: Comparison of five models to scale daily evapotranspiration from one-time-of-day measurements, Trans. ASAE, 49, 1409-1417, doi:10.13031/2013.22056, 2006.

Crago, R. D.: Conservation and variability of the evaporative fraction during the daytime, J. Hydrol., 180, 173-194, doi:10.1016/0022-1694(95)02903-6, 1996.

Dahmani, K., Notton, G., Voyant, C., Dizene, R., Nivet, M. L., Paoli, C., and Tamas, W.: Multilayer Perceptron approach for estimating 5-min and hourly horizontal global irradiation from exogenous meteorological data in locations without solar measurements, Ren. Energ., 90, 267-282. doi:10.1016/j.renene.2016.01.013, 2016.

Delogu, E., Boulet, G., Olioso, A., Coudert, B., Chirouze, J., Ceschia, E., Le Dantec, V., Marloie, O., Chehbouni, G., and Lagouarde, J.-P.: Reconstruction of temporal variations of evapotranspiration using instantaneous estimates at the time of satellite overpass, Hydrol. Earth Syst. Sci., 16, 2995-3010, doi:10.5194/hess-16-2995-2012, 2012.

Foken, T., Wimmer, F., Mauder, M., Thomas, C., and Liebethal, C.: Some aspects of the energy balance closure problem, Atmos. Chem. Phys., 6, 4395-4402, doi:10.5194/acp-6-4395-2006, 2006.

Franssen, H. J. H., Stöckli, R., Lehner, I., Rotenberg, E., and Seneviratne, S. I.: Energy balance closure of eddy-covariance data: A multisite analysis for European FLUXNET stations, Agr. Forest Meteorol., 150, 1553-1567, doi:10.1016/j.agrformet.2010.08.005, 2010.

Gardner, M. W. and Dorling, S. R.: Artificial neural networks (the multilayer perceptron) - a review of applications in the atmospheric sciences, Atmos. Environ., 32, 2627-2636, doi:10.1016/S1352-2310(97)00447-0, 1998.

Gentine, P., Entekhabi, D., Chehbouni, A., Boulet, G., and Duchemin, B.: Analysis of evaporative fraction diurnal behaviour, Agr. Forest Meteorol., 143, 13-29, doi:10.1016/j.agrformet.2006.11.002, 2007.

Harper, A., Baker, I. T., Denning, A. S., Randall, D. A., Dazlich, D., and Branson, M.: Impact of Evapotranspiration on Dry Season Climate in the Amazon Forest, J. Climate, 27, 574-591, doi:10.1175/JCLI-D-13-00074.1, 2014. 
Hasni, A., Sehli, A., Draoui, B., Bassou, A., and Amieur, B.: Estimating Global Solar Radiation Using Artificial Neural Network and Climate Data in the South-western Region of Algeria, Energy Proc., 18, 531-537, doi:10.1016/j.egypro.2012.05.064, 2012.

Hildebrandt, A., Aufi, M. A., Amerjeed, M., Shammas, M., and Eltahir, E. A. B.: Ecohydrology of a seasonal cloud forest in Dhofar: 1. Field experiment, Water Resour. Res., 43, W10411, doi:10.1029/2006WR005261, 2007.

Hoedjes, J. C. B., Chehbouni, A., Jacob, F., Ezzahar, J., and Boulet, G.: Deriving daily evapotranspiration from remotely sensed instantaneous evaporative fraction over olive orchard in semi-arid Morocco, J. Hydrol., 354, 53-64, doi:10.1016/j.jhydrol.2008.02.016, 2008.

Huang, G., Liu, S., and Liang, S.: Estimation of net surface shortwave radiation from MODIS data, Int. J. Remote Sens., 33, 804825, doi:10.1080/01431161.2011.577834, 2012.

Jackson, R. D., Hatfield, J. L., Reginato, R. J., Idso, S. B., and Pinter Jr., P. J.: Estimation of daily evapotranspiration from one time-of-day measurements, Agr. Water Manag., 7, 351-362, doi:10.1016/0378-3774(83)90095-1, 1983.

Khatib, T., Mohamed, A., and Sopian, K.: A review of solar energy modeling techniques, Ren. Sust. Energy Rev., 16, 2864-2869, doi:10.1016/j.rser.2012.01.064, 2012.

Kim, Y., Knox, R. G., Longo, M., Medvigy, D., Hutyra, L. R., Pyle, E. H., Wofsy, S. C., Bras, R. L., and Moorcroft, P. R.: Seasonal carbon dynamics and water fluxes in an Amazon rainforest, Glob. Change Biol., 18, 1322-1334, doi:10.1111/j.13652486.2011.02629.x, 2012.

Laine, V., Venäläinen, A., Heikinheimo, M., and Hyvärinen, O.: Estimation of Surface Solar Global Radiation from NOAA AVHRR Data in High Latitudes, J. Appl. Meteorol., 38, 1706-1719, 1999.

Lazzús, J. A., Pérez Ponce, A. A., and Marin, J.: Estimation of global solar radiation over the city of La Serena (Chile) using a neural network, Appl. Sol. Ener., 47, 66-73, doi:10.3103/S0003701X11010099, 2011.

Li, M.-F., Tang, X.-P., Wu, W., and Liu, H.-B.: General models for estimating daily global solar radiation for different solar radiation zones in mainland China, Energ. Conv. Manag., 70, 139148, doi:10.1016/j.enconman.2013.03.004, 2013.

Loew, A., Peng, J., and Borsche, M.: High-resolution land surface fluxes from satellite and reanalysis data (HOLAPS v1.0): evaluation and uncertainty assessment, Geosci. Model Dev., 9, 24992532, doi:10.5194/gmd-9-2499-2016, 2016.

Lopez, G. and Batlles, F. J.,: Estimating solar radiation from MODIS data, Energ. Proc., 49, 2362-2369, doi:10.1016/j.egypro.2014.03.250, 2014.

Malek, E.: Night-time evapotranspiration vs. daytime and $24 \mathrm{~h}$ evapotranspiration, J. Hydrol., 138, 119-129, doi:10.1016/00221694(92)90159-S, 1992.

Mallick, K., Jarvis, A., Wohlfahrt, G., Kiely, G., Hirano, T., Miyata, A., Yamamoto, S., and Hoffmann, L.: Components of nearsurface energy balance derived from satellite soundings - Part 1: Noontime net available energy, Biogeosciences, 12, 433-451, doi:10.5194/bg-12-433-2015, 2015.

Mauder, M. and Foken, T.: Impact of post-field data processing on eddy covariance flux estimates and energy balance closure, Meteorol. Z., 15, 597-609, doi:10.1127/0941-2948/2006/0167, 2006.
McCulloch, W. S. and Pitts, W.: A logical calculus of the ideas immanent in nervous activity, Bull. Math. Biophys., 5, 115-133, doi:10.1007/BF02478259, 1943.

Mubiru, J. and Banda, E. J. K. B.: Estimation of monthly average daily global solar irradiation using artificial neural networks, Sol. Energy, 82, 181-187, doi:10.1016/j.solener.2007.06.003, 2008.

Parlange, M. B. and Katul, G. G.: Estimation of the diurnal variation of potential evaporation from a wet bare soil surface, J. Hydrol., 132, 71-89, doi:10.1016/0022-1694(92)90173-S, 1992.

Polo, J., Zarzalejo, L., and Ramírez, L.: Solar Radiation Derived from Satellite Images, in: Modeling Solar Radiation at the Earth's Surface SE, edited by: Badescu, V., Springer Berlin Heidelberg, 18, 449-462, doi:10.1007/978-3-540-77455-6_18, 2008.

Ryu, Y., Baldocchia, D. D., Black, T., Detto, M., Law, B. E., Leuning, R., Miyata, A., Reichstein, M., Vargas, R., Ammann, C., Beringer, J., Flanagan, L. B., Gu, L., Hutley, L. B., Kim, J., McCaughey, H., Moors, E. J., Rambal, S., and Vesala, T.: On the temporal upscaling of evapotranspiration from instantaneous remote sensing measurements to 8 day mean daily-sums, Agr. Forest Meteorol., 152, 212-222, doi:10.1016/j.agrformet.2011.09.010, 2012.

Senay, G. B., Velpuri, N. M., Bohms, S., Budde, M., Young, C., Rowland, J., and Verdin, J. P.: Drought Monitoring and Assessment: Remote Sensing and Modeling Approaches for the Famine Early Warning Systems Network, in: Hydro-Meteorological Hazards, Risks, and Disasters, 233-262, doi:10.1016/B978-012-394846-5.00009-6, 2015.

Sepulcre-Canto, G., Vogt, J., Arboleda, A., and Antofie, T.: Assessment of the EUMETSAT LSA-SAF evapotranspiration product for drought monitoring in Europe, Int. J. Appl. Earth Obs. Geoinf., 30, 190-202, doi:10.1016/j.jag.2014.01.021, 2014.

Shuttleworth, W. J., Gurney, R. J., Hsu, A. Y., and Ormsby, J. P.: FIFE: the variation in energy partition at surface flux sites, IAHS Publ., 186, 67-74, 1989.

Tang, R., Li, Z.-L., and Sun, X.: Temporal upscaling of instantaneous evapotranspiration: An intercomparison of four methods using eddy covariance measurements and MODIS data, Remote Sens. Environ., 138, 102-118, doi:10.1016/j.rse.2013.07.001, 2013.

Tang, R., Tang, B., Wu, H., and Li, Z. L.: On the feasibility of temporally upscaling instantaneous evapotranspiration using weather forecast information, Int. J. Remote Sens., 36, 19-20, doi:10.1080/01431161.2015.1029597, 2015.

Tolk, J, A., Howell, T. A., and Evett, S. R.: Nighttime evapotranspiration from alfalfa and cotton in a semiarid climate, Agron. J., 98, 730-736, doi:10.2134/agronj2005.0276, 2006.

Van Niel, T. G., McVicar, T. R., Roderick, M. L., van Dijk, A. I. J. M., Beringer, J., Hutley, L. B., and van Gorsel, E.: Upscaling latent heat flux for thermal remote sensing studies: Comparison of alternative approaches and correction of bias, J. Hydrol., 468469, 35-46, doi:10.1016/j.jhydrol.2012.08.005, 2012.

Wang, D., Liang, S., He, T., Cao, Y., and Jiang, B.: Surface Shortwave Net Radiation Estimation from FengYun-3 MERSI Data, Remote Sens., 7, 6224-6239, doi:10.3390/rs70506224, 2015.

Wang, S.-C.: Artificial Neural Network, in: Interdisciplinary Computing in Java Programming SE, Springer US, 5, 743, 81-100, doi:10.1007/978-1-4615-0377-4_5, 2003. 
Wilson, K., Goldstein, A., Falge, E., Aubinet, M., Baldocchi, D., Berbigier, P., Bernhofer, C., Ceulemans, R., Dolman, H., Field, C., Grelle, A., Ibrom, A., Law, B. E., Kowalski, A., Meyers, T., Moncrieff, J., Monson, R., Oechel, W., Tenhunen, J., Valentini, R., and Verma, S.: Energy balance closure at FLUXNET sites, Agr. Forest Meteorol., 113, 223-243, doi:10.1016/S01681923(02)00109-0, 2002.

Xu, T., Liu, S., Xu, L., Chen, Y., Jia, Z., Xu, Z., and Nielson, J.: Temporal Upscaling and Reconstruction of Thermal Remotely Sensed Instantaneous Evapotranspiration, Remote Sens., 7, 3400, doi:10.3390/rs70303400, 2015. 